\title{
Motivating bureaucrats through social recognition: External validity-A tale of two states
}

\author{
Varun Gauri $^{\mathrm{a}}$, Julian C. Jamison ${ }^{\mathrm{b}}$, Nina Mazar ${ }^{\mathrm{c}}$, Owen Ozier ${ }^{\mathrm{d}, *}$ \\ ${ }^{\mathrm{a}}$ Mind, Behavior, and Development (eMBeD), The World Bank, United States \\ ${ }^{\mathrm{b}} J-P A L, e M B e D$, and University of Exeter, United Kingdom \\ ${ }^{\mathrm{c}}$ Boston University, United States \\ ${ }^{\mathrm{d}}$ BREAD, IZA, and Human Development Team, Development Research Group, The World Bank, United States
}

A R T I C L E I N F O

\section{JEL classification:}

C93

D73

D91

I18

L38

$\mathrm{O} 35$

\section{Keywords:}

RCT

External validity

Bureaucracy

Behavioral insights

Nudges

Healthcare

\begin{abstract}
A B S T R A C T
Bureaucratic performance is a crucial determinant of economic growth, but little real-world evidence exists on how to improve it, especially in resource-constrained settings. We conducted a field experiment of a social recognition intervention to improve record keeping in health facilities in two Nigerian states, replicating the intervention implemented by a single organization - on bureaucrats performing identical tasks. Social recognition improved performance in one state but had no effect in the other, highlighting both the potential benefits and also the sometimes-limited generalizability of behavioral interventions. Furthermore, differences in facility-level observables did not explain cross-state differences in impacts, suggesting that it may often be difficult to predict external validity.
\end{abstract}

\section{Introduction}

Public spending on health and education can occupy as much as one third of developing country government budgets, but long-standing concerns surround the effectiveness of this expenditure (World Bank, 2004, Reinikka \& Svensson, 2004). Effective bureaucracies are crucial for economic growth and poverty reduction (Evans \& Rauch, 1999), but what makes individual bureaucrats more productive remains an open question for research. To motivate individual bureaucrats, governments typically use a combination of meritocratic recruitment, professional standards, laws and civil service codes, wages and bonuses, and longterm career rewards. The most suitable mix of incentives likely depends, among other things, on aspects of the bureaucratic task at hand, especially task complexity and the extent to which discretion on the part of the bureaucrat is important, as well as on the information available to political principals and on the observability of bureaucratic performance (Aghion \& Tirole, 1997). As a result, there have been waves of management approaches and philosophies that emphasize certain incentive schemes, often at the expense of others.
For specific, observable tasks, for example, some public organizations have introduced bonus pay (see Basinga et al., 2011; Muralidharan \& Sundararaman, 2011; et cetera). Monetary awards, however, can be expensive to implement, particularly for developing country governments. Further, they could even crowd out other important tasks, or cause cream skimming of easier-to-work-with clients (Prendergast, 1999). Recently, behavioral economists have begun to examine the use of less expensive, targeted interventions when bureaucrats need to achieve specific tasks. Sometimes these take the form of reminders and other kinds of choice architecture or "nudges," which have been shown to be cost-effective in achieving various policy goals in the US and UK (Benartzi et al., 2017). Social recognition can be considered as one type of nudge, whether in the form of certificates for "employee of the month," public ceremonies, or other kinds of appreciation (e.g., Ashraf, Bandiera, \& Jack, 2014).

In this paper we present a field experiment that we conducted to test the effectiveness of one such behavioral incentive, a performancecontingent social recognition intervention to increase performance on an important task undertaken by health facility staff in Nigeria: the tracking of income and expenditure resource streams at primary health

\footnotetext{
* Corresponding author.

E-mail addresses: vgauri@worldbank.org (V. Gauri), j.jamison@exeter.ac.uk (J.C. Jamison), nina@ninamazar.com (N. Mazar), oozier@worldbank.org (O. Ozier).
} 
care (PHC) facilities (clinics, posts, and health centres). Specifically, the four week long intervention consisted of posting PHC facilities' weekly performance through a number of "stars" on a prominently displayed "Certificate of Excellence" within the facility. In addition, the best performing facility was promised a public award ceremony with the Permanent Secretary of Health.

The overall goal of our trial was to overcome weak accountability structures that can lead to 'leakage', and this particular instantiation matters enough that there is a larger collaboration between the government of Nigeria and the World Bank focused on it. Working with the government, we rigorously evaluated a behavioral science approach by carrying out the same intervention in a random subset of facilities within two different states in the country (Ekiti and Niger), allowing us to directly test not only the intervention but, more importantly, also the generalizability of the results. Furthermore, we exploited survey data at the facility level to examine not only which factors influence performance on expenditure tracking but also the relative success of the intervention across environments.

In a nutshell, we found that our relatively inexpensive social recognition intervention motivated bureaucrats in one of the two states yet showed no effect in the other. Note that the dependent variable - the task of tracking resources at the facility -was quite basic, so a successful intervention may be unsurprising, but that makes the lack of success in the other state harder to explain. None of our observable variables could explain the difference in treatment effects between states.

We contribute to several strands of literature. First, in addition to examining a social recognition intervention, our top-level treatment effects add to literatures on incentives within bureaucracies (including preventing corruption) and on the possible scope for behavioral interventions in developing countries. As a secondary contribution along these lines, we contribute to the literature on interventions aimed at health systems in developing countries. The recent work of Dunsch, Evans, Eze-Ajoku, and Macis (2017), for example, relates closely to ours, in trying to improve practices within health systems in Nigeria. In alignment with the findings in that paper, we find larger effects among the simpler sub-tasks within the broader set of resource tracking measures we capture.

Finally, we contribute to the growing literature on external validity in development economics and behavioral sciences. Though generalizability is not a challenge specific to randomized trials, this trial presented an opportunity to examine generalizability more directly than is often feasible. We tested whether observable characteristics at the facility level (e.g., geographic distance between facilities, staff resources, educational attainment of the local population), were predictive not only of levels and treatment effect heterogeneity within a single state, but also of the difference in treatment effects across states, holding constant the implementing organization. Given the lack of explanatory power of our variables, we interpret our findings to imply that social recognition can be an effective and relatively low-cost tool to motivate bureaucrats to complete a specific task such as record keeping, but that its effects are dependent on social milieu and institutional structures in ways that are difficult to measure. Our contribution is thus not only an examination of behavioral incentive schemes in an important and novel policy context, but also a next step in the assessment of external validity in field experiments.

\subsection{Existing literature}

The idea that individuals are motivated by public and peer recognition is not new. ${ }^{1}$ Social recognition and peer appreciation can have internal effects on motivation, by highlighting what Cassar and Meier (2018) call "feelings of relatedness" in job design, or external effects on motivation, through the attribution of recognition to potential career trajectories. The notion that individuals crave status has long been studied and has more recently been formalized (Moldovanu, Sela, \& Shi, 2007; Besley \& Ghatak,

\footnotetext{
${ }^{1}$ See, for example, Hobbes (1651) Leviathan, Chapter 17: "men are continually in competition for honour and dignity" - cited in Hirschman (1973).
}

2008; Kosfeld \& Neckermann, 2011) and reviewed (Ashraf and Bandiera, 2018). Psychologists sometimes worry that monetary rewards can indirectly crowd out the valuable intrinsic motivation of agents, whereas recognition is comparatively less likely to do so (Ryan and Deci, 2000). It is even possible that recognition may enhance such intrinsic motivation, for instance by making the positive attributes of the effort more salient. Even without such a mechanism, recognition and other non-pecuniary incentives can enhance reputations, spur competitive behavior, and/or simply be valued in their own right.

There is consistent empirical evidence to show that employees value recognition (for a metaanalysis see Stajkovic and Luthans, 1997; also, see Larkin, 2011). For example, Nelson (2001) reviewed studies that identified 'appreciation' and 'recognition' as being more important than traditional incentives such as 'good wages' and 'job security' or 'promotion opportunities.' This observation remains true in developing countries, where financial constraints are especially binding. A number of studies on developing countries suggest that non-financial incentives such as 'recognition' are important drivers of employee behavior (Mathauer \& Imhoff, 2006; Stilwell 2001); for evidence that negative recognition - e.g., peer exposure of non-compliant companies - can also improve behavior, see Chetty, Mobarak, and Singhal (2014) in Bangladesh.

Specifically regarding the health sector, Mathauer and Imhoff (2006) engaged in detailed semi-structured qualitative interviews with staff from healthcare facilities from public, private, and non-governmental organization (NGO) facilities in rural areas of Benin. They concluded that health workers highly valued recognition and appreciation from superiors and colleagues as well as patients. Furthermore, this valuation did not differ by the type of institution (private, public, or NGO).

Finally, and perhaps most directly relevantly, in a field experiment run in Zambia in collaboration with a public health organization, Ashraf et al. (2014) randomized 800 community agents hired to sell condoms in urban compounds into four monetary and nonmonetary performance contingent reward treatments. Agents who were assigned to the nonmonetary reward treatment-namely, stars for performance plus a public ceremony for top performers-sold twice as many condoms as agents who were offered a modest financial margin on each pack sold. Such a study could help in public service contexts where management and performance could benefit from new techniques of motivation due to, for example, limited financial resources.

In their review of the social incentives literature, Ashraf and Bandiera (2018) conclude that the positive effect of social incentives on performance is large, ranging between 7 and 16 percent, but that its sign depends on the social group implicated in the social incentives as well as the nature of the agents' social preferences that underpin them (for the latter see also recent work by Butera, Metcalfe, Morrison, and Taubinsky (2019) about the role of the shape of the social recognition utility function for quantifying the social efficiency of using social recognition in comparison to financial incentives for behavior change). Specifically, in a context like ours, where the health facility's accounting performance was to be publicly displayed to a vertical social group (i.e. non-peers; all visitors and other types of health facility employees), social incentives typically increase performance. In addition, relevant to our low-capacity context, in a study of the Nigerian civil service, Rasul and Rogger (2018) find that 38\% of public sector projects never start, compared to $31 \%$ that actually finish, and Khemani (2006) finds substantial levels of non-payment of salaries to primary health care providers in Nigeria, as well as state-level variation in the same. Therefore, the public posting of a prominent number of stars to quantify and reward performance including a public ceremony, as used in Ashraf et al. (2014) experiment, served as the inspiration for the specific social recognition intervention in the present study.

\subsection{External validity}

The first time an intervention is shown to be effective (or not) in any given setting has been of substantially greater interest to academic audiences-and has been accompanied by substantially greater rewards for 
academic authors-than is any subsequent attempt to replicate the finding (Galiani, Gertler, \& Romero, 2018). For policymakers, however, information about when and where the intervention works, and for whom, is just as important as the initial finding. Indeed, this point applies more broadly than just to field experiments or program evaluation per se. A prominent recent example of different treatment effects in otherwise similar settings is that of the intergenerational effects of incarceration, examined in Sweden and in Norway (see Dobbie, Goldon, \& Yang, 2018; Bhuller, Dahl, Loke, \& Mogstad, 2018, respectively).

In our context, as in most situations, there are different possibilities regarding the exact mechanism underlying social recognition, some of which can be informed by sufficiently rich data on covariates. We have a more complete set of accompanying administrative data than is typical, though it is not complete (especially in terms of what would be needed for many behavioral models), and we use that to empirically ascertain three things: first, whether these covariates are predictive of the levels of the outcome in the absence of the intervention; second, whether these covariates are predictive of the impact of the intervention; and third, most crucially, whether the estimation of heterogeneous treatment effects allows us to predict the treatment effect across state boundaries. We are able to perform this last step, which appears relatively uncommon in field experiments, because we were able to implement the same intervention in the same manner and by the same organization in two different settings (in our case states within a federal country).

Hence, in engaging the recent literature on external validity, this study addresses two key issues. First, in relation to the work of Bold, et al. (2013), who show that different implementers have different effects in the same country, and Das, Friedman, and Kandpal (2018), who show that implementers and populations both explain differences in effects, we are able to show that even for a single implementer in a single country, very different treatment effects are obtained in different states. One need not turn to implementer quality as an explanation, when the implementer is the same. Second, in relation to the work of Bates and Glennerster (2017) and Andrews and Oster (2017), we unsurprisingly show that there are multiple covariates that predict the outcome (quality of record-keeping). However, despite that relative wealth of predictive covariates, we find a scarcity of covariates that are predictive of the treatment effect. Further, we find that none of those predictive covariates predict both the treatment effect and the difference in treatment effects across states. This suggests that even when covariates that could be logically connected to the outcome indeed prove to be statistically predictive of the outcome in question, these covariates are not necessarily predictive of either within-setting or across-setting treatment effect heterogeneity. Thus, they may not be sufficient to translate treatment effects from one setting to another. Some other structural variables, potentially more difficult to quantify, such as the nature of the individuals' underlying social preferences (Ashraf and Bandiera, 2018; Butera et al., 2019), may drive heterogeneity in effects across settings.

\section{Experimental background}

In Nigeria as elsewhere, record-keeping is generally viewed as a mundane task, with no broader pro-community mission acting as a motivating factor to undertake the task. There is no existing incentive for better resource tracking. In fact, there may even be perverse incentives to further highlight a situation of scarcity - with the assumption that under-reporting of resources could lead to more assistance especially from development partners. In addition, there is a structural weakness to enforce accountability. Very rarely does a fear of supervision exist that makes facility officers ensure records are maintained, to protect themselves from corruption allegations.

The importance of record keeping, in the Nigerian context, stems from several factors. First and foremost is the fact that the government of Nigeria has struggled to reliably track how much it spends on primary healthcare. This is partly because classifications of expenditure in the health sector tend to be too broad to capture such granular but vital information, but also because the resources (cash and in-kind) that flow to primary healthcare in the country are heavily fragmented, with no system in place to aggregate them into central databases. This means that it is important to devise alternative ways of tracking income and expenditure in the sector. In an effort to help Nigeria with that development, the World Bank introduced an innovative continuous Public Expenditure Tracking Survey (PETS) and Resource Tracking (RT) exercise in two states (Ekiti and Niger), which recorded and aggregated information on resource flows in real time, rather than following the more established practice of retrospectively generating such data. In both states, the intervention and the monitoring were conducted by the same local firm. ${ }^{2}$

The need is especially great at the primary facility level, for which no entity above the facility level - including local government and state authorities - has reliable information on income and expenditure streams. One of the central issues identified by previous studies is the weakness of accountability structures at the facility level - a gap that a World Bank-financed intervention is attempting to address. The main contribution of the PETS/RT has been to design and introduce relatively simple-to-fill-out forms (spreadsheets; other resource tracking tools) to track various income and expenditure streams. This includes, for example, creation of a standardized cash book form (for the recording of cash receipts from user charges e.g., consultation fees, laboratory tests, and drug sales and expenditures such as due to purchases of drugs, equipment, materials, or supplies, wages, and facility maintenance), accompanied by training for staff at the facility level on how to fill out these forms on a daily basis.

However, absent sufficient motivation, the introduction of resource tracking forms (and instruction in their use) is not likely to change bureaucratic behavior at the facility level. In an important sense, the larger agenda regarding transparency and anti-corruption in countries such as Nigeria depends, in part, on the motivation of bureaucrats to complete their record keeping tasks. Indeed, accountability and the reduction of 'leakage' is another explicit factor in the importance of careful tracking of monetary inflows and outflows among civil servants. Without full tracking of cash flows, it is relatively easy to divert funds illicitly. Of course, filling out a form does not in itself guarantee accuracy, and dedicated agents could still manage to enrich themselves, but being forced to explicitly report fraudulently adds an additional barrier (both psychological and formal; Mazar \& Hawkins, 2015).

In the face of this challenge, the literature discussed above suggests that targeted interventions, such as social recognition, can be effective motivators of behavioral change for public officials as well as for consumers and citizens. Based on these insights, the clear need in the Nigerian setting, and a growing body of evidence showing that "nudges" to influence behavioral choices can be used to address problems in public service delivery (Ashraf, 2013; Thaler \& Sunstein, 2008; World Bank, 2015; see also Ashraf, Bandiera, \& Lee, 2016), we designed a randomized control trial (RCT) in which we tested in the field the effectiveness of a social incentive intervention to improve performance of record-keeping at medical facilities in Nigeria. In particular, we extended the PETS/RT exercise in the two states Ekiti and Niger, focusing on the quality with which facility staff filled out the cash book form. The feasibility of the possible implementation of the intervention beyond the study period was an important consideration in its choice and design.

\section{Data and experimental design}

In 2015, the World Bank and the Government of Nigeria embarked on a collaboration to verify that resources - funds, equipment, medication, and so forth - are received at public health facilities in the same quantities that they are sent by state and central government ministries. This exercise involved regularly visiting a set of 140 facilities across two of Nigeria's 36 states, Ekiti and Niger (see Fig. 1 and Appendix Fig. A5) to measure stocks

\footnotetext{
${ }^{2}$ The local firm carrying out this work was Hanovia Medical Ltd., Nigeria.
} 


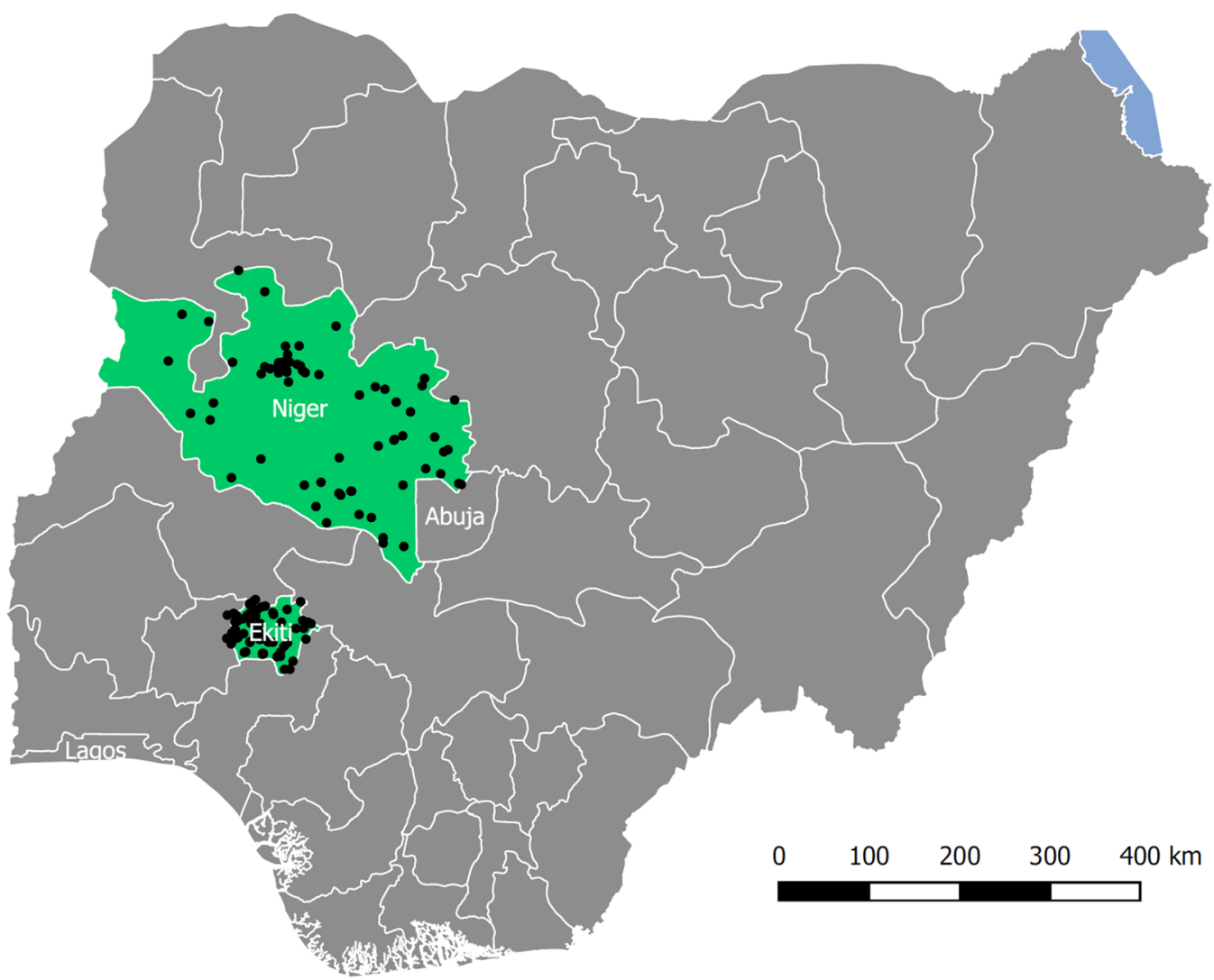

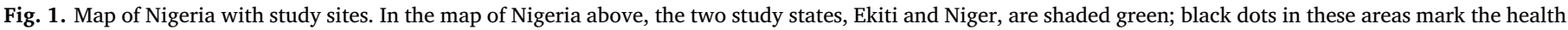
facilities included in the study. The federal capital, Abuja, and the largest city, Lagos, are both labeled.

and recent flows of resources. Basic summary statistics about these facilities are shown in Table 1. Most of the facilities are rural, and are open five days a week, eight or more hours a day. About one third of the facilities have access to electricity, most have running water, but virtually none has a landline or mobile phone specific to the facility.

There are some differences across the two states in these characteristics, also shown in Table 1. Facilities in Ekiti are larger, open more days per week, and open more hours per day than those in Niger. A comparable fraction of facilities in each state are categorized as rural, however, and while neither state's facilities are very likely to have access to electricity, both states' facilities are likely to have access to water. The two states differ in many other ways; Ekiti is more densely populated than Niger, for example: the former has a population density comparable to that of Rwanda; the latter, lower than that of Kenya.

In light of the motivation and goals described above, we devised a behavioral intervention that could be tested in the two states: social recognition for good performance. From January to March 2016, we tested the intervention in an RCT. The study leveraged the ongoing resource tracking study across the two states. Because the underlying expenditure-tracking survey was happening regardless, our intervention had a very low marginal cost. In other environments it might be necessary to leverage existing visits of different types, perhaps involving a lower frequency of monitoring.

Thus, we randomly assigned a total of 140 facilities in the two states to two arms per state for the purposes of this RCT, to find out whether the program could improve record-keeping. To maximize the study's statistical power, we assigned half of the facilities to each arm in each state. To ensure that geography would not confound analysis, we stratified this randomization by state, and within state, by local government authorities (LGA); meaning that we randomized the facilities to arms within each LGA. Nigerian LGAs are the lowest of three tiers of Nigerian government, situated below the federal and state levels (Khemani, 2006). We stratify on 16 LGAs in Ekiti and 23 in Niger, so this was stricter than stratifying by state.

In Table 2, we show balance tests for the observables that, ex ante, we hypothesized might be responsible for heterogeneity in treatment effects. We do this for the entire sample, and separately by state. Most covariates are balanced at conventional statistical levels, but the logarithm of monthly outpatients is imbalanced in Ekiti, and the presence of designated staff for financial accounting is imbalanced in Niger.

The treatment "arm" provides social recognition as an incentive based on scoring the facilities' record-keeping qualities. The record in question was the cash book form, a simple excel balance sheet that tracked the cash receipts from user charges as well as expenditures, by category, on a daily basis. The quality of those records could be assessed by enumerators who visited the facilities on a weekly basis. The precise design of the evaluation was as follows.

For four weeks of the incentives study, the two study arms being compared were

A. Control. Records were scored weekly by enumerators; however, scores were not publicly shared.

B. Social Recognition. Records were scored weekly by enumerators; scores were then converted to a number of stars between 0 and 5 . The stars were displayed in a public place on a "Certificate of Excellence" for anyone visiting the facility to see (for a picture of the certificate, see Appendix Fig. A1; for examples of their display, see Appendix Fig. A4). Furthermore, the social recognition treatment was comparative - at the end of the experimental period the bestperforming facility and all staff members who participated in completing the cash book form were commended and posed for photographs and an honorable handshake with the Permanent Secretary of Health in a special ceremony, and this was explained in advance.

At the fifth week of the study, an additional incentive program 
Table 1

Summary statistics by state.

\begin{tabular}{|c|c|c|c|c|c|c|c|}
\hline \multirow[b]{2}{*}{ Dependent variable } & \multicolumn{3}{|l|}{ Ekiti } & \multicolumn{3}{|c|}{ Niger } & \multirow[b]{2}{*}{ p-value } \\
\hline & Obs. & Mean & S.D. & Obs. & Mean & S.D. & \\
\hline Rural (indicator) & 65 & 0.86 & 0.35 & 75 & 0.88 & 0.33 & 0.748 \\
\hline Total No of Beds & 65 & 6.75 & 4.44 & 75 & 3.11 & 3.55 & $0.000 * * *$ \\
\hline Electricity availability & 65 & 0.37 & 0.44 & 75 & 0.27 & 0.38 & 0.17 \\
\hline Water availability & 65 & 0.82 & 0.36 & 75 & 0.89 & 0.3 & 0.214 \\
\hline Toilet availability & 65 & 0.72 & 0.44 & 75 & 0.52 & 0.49 & $0.011^{* *}$ \\
\hline Log(monthly outpatients) & 64 & 4.53 & 0.94 & 75 & 4.99 & 1.19 & $0.012^{* *}$ \\
\hline Outpatient gender ratio & 63 & 3.98 & 1.73 & 75 & 3.39 & 1.56 & $0.039 * *$ \\
\hline Patient education (secondary + ) & 61 & 0.7 & 0.21 & 69 & 0.43 & 0.33 & $0.000^{* * *}$ \\
\hline Number of days open per week & 65 & 6.28 & 0.96 & 75 & 5.28 & 0.69 & $0.000^{* * *}$ \\
\hline Number of hours open per day & 65 & 14.33 & 7.18 & 75 & 6.97 & 2.49 & $0.000^{* * *}$ \\
\hline Population density (per $\mathrm{km}^{2}$ ) & 65 & 471.28 & 216.36 & 75 & 270.8 & 744.14 & $0.028^{* *}$ \\
\hline Staff for financial accounting & 65 & 0.58 & 0.5 & 75 & 0.12 & 0.33 & $0.000^{* * *}$ \\
\hline Number of staff listed on roster & 65 & 10.74 & 7.26 & 75 & 4.72 & 5.55 & $0.000^{* * *}$ \\
\hline Fraction female among staff & 65 & 0.89 & 0.16 & 75 & 0.47 & 0.36 & $0.000^{* * *}$ \\
\hline
\end{tabular}

In the table above, for each variable, the number of observations, mean for the variable, and standard deviation of the variable are reported separately for facilities in Ekiti and Niger state. The last column reports the p-value for the test of equality of the means in the two states. * denotes significance at the $10 \%$ level, ** at the $5 \%$ level, and *** at the $1 \%$ level. The table is broken into four sections. The first section reports basic characteristics of the facilities; electricity, water, and toilets are coded $1=$ available, $0=$ unavailable, and $0.5=$ not available "right now." The second, third, and fourth sections report variables against which we may be interested in testing for treatment effect heterogeneity. The first variable is the natural logarithm of the average number of outpatients per month seen in a sevenmonth period, October 2015 - April 2016. Outpatient gender ratio is reported as female/male. Patient education is calculated as the average over patient exit surveys conducted by the research team at the facility. Population density is calculated at the Local Government Authority (LGA) level from Nigeria's 2006 census.

Table 2

Tests of covariate balance across treatment arms.

\begin{tabular}{|c|c|c|c|c|c|c|c|c|c|}
\hline \multirow[b]{2}{*}{ Dependent variable } & \multicolumn{3}{|c|}{ Both states } & \multicolumn{3}{|l|}{ Ekiti } & \multicolumn{3}{|l|}{ Niger } \\
\hline & $\begin{array}{l}\mathrm{C} \\
\mathrm{N}=71\end{array}$ & $\begin{array}{l}\mathrm{T} \\
\mathrm{N}=69\end{array}$ & p-value & $\begin{array}{l}\mathrm{C} \\
\mathrm{N}=33\end{array}$ & $\begin{array}{l}\mathrm{T} \\
\mathrm{N}=32\end{array}$ & p-value & $\begin{array}{l}\mathrm{C} \\
\mathrm{N}=38\end{array}$ & $\begin{array}{l}\mathrm{T} \\
\mathrm{N}=37\end{array}$ & p-value \\
\hline Log(monthly outpatients) & 4.74 & 4.81 & 0.7184 & 4.20 & 4.89 & $0.0027^{* * *}$ & 5.22 & 4.75 & $0.0950 *$ \\
\hline Outpatient gender ratio & 3.41 & 3.92 & $0.0734 *$ & 3.65 & 4.32 & 0.1236 & 3.21 & 3.58 & 0.3209 \\
\hline Patient education (secondary + ) & 0.57 & 0.54 & 0.5697 & 0.72 & 0.68 & 0.4578 & 0.45 & 0.40 & 0.5405 \\
\hline Number of days open per week & 5.7 & 5.79 & 0.5847 & 6.12 & 6.44 & 0.1859 & 5.34 & 5.22 & 0.4588 \\
\hline Number of hours open per day & 9.98 & 10.88 & 0.4066 & 13.64 & 15.05 & 0.4317 & 6.80 & 7.18 & 0.5273 \\
\hline Staff for financial accounting & 0.35 & 0.32 & 0.7240 & 0.52 & 0.66 & 0.2549 & 0.21 & 0.03 & $0.0140 * *$ \\
\hline Number of staff listed on roster & 7.82 & 7.26 & 0.6482 & 10.30 & 11.19 & 0.6282 & 5.66 & 3.78 & 0.1493 \\
\hline Fraction female among staff & 0.71 & 0.62 & 0.1506 & 0.91 & 0.88 & 0.3580 & 0.54 & 0.40 & 0.1090 \\
\hline
\end{tabular}

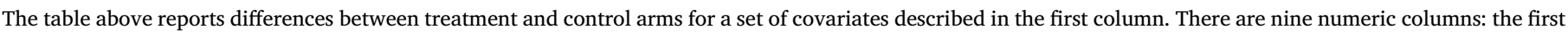

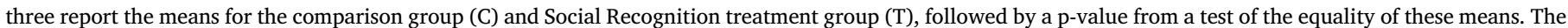

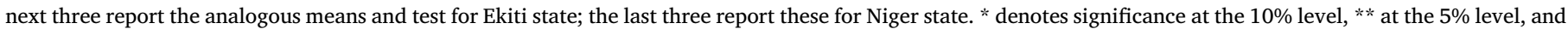
$* * *$ at the $1 \%$ level.

began in the Control group facilities, concluding this experiment. This change was not announced in advance. The randomized design permits us to attribute any differences in performance over these four weeks (post-baseline) to the Social Recognition scheme.

\subsection{Data}

To measure performance, we gathered a weekly dataset on the quality of the cash book record-keeping. The scoring "checklist," which assessed the quality of the records, focused on whether the cash book had been filled out at all prior to arrival; how complete its various sections were; and how consistent it was with other documentation (including other forms and paper receipts); Based on the answers to these questions, the checklist produced a weekly score for each facility. ${ }^{3}$

\footnotetext{
${ }^{3}$ For details on the exact questions, see Appendix A. Note that one of the questions, question 8 links the main "cash book" form to a different form which records dates and quantities for any drug shipments that the facility receives, whether locally purchased or regionally distributed; this link allows an enumerator to check both forms (cash book and drug purchases) for consistency on
}

\subsection{Implementation details}

Enumerators already making weekly visits to facilities for the larger PETS/RT project were trained on our social incentive intervention. Each enumerator visited on average four or five facilities each week, which could include sample facilities from the Control group, the Social Recognition group, or both.

Facilities in the Social Recognition group were expected to display their Certificate of Excellence in a prominent spot at the facility (see Appendix A4 for sample photographs), so that their weekly performance (or lack of it) would be visible to all. The assumption here was that staff would be motivated to work better at filling out the cash book form because of the desire to earn stronger community approbation (quality-contingent social reward), and/or recognition from their community (e.g., visitors, patients, other facility staff members).

(footnote continued)

at least the arrival of drugs in the facility on a given day. The distribution of scores is shown in Appendix Fig. A3. 


\section{Results}

We begin with results from the RCT, reporting separately in Ekiti and Niger. Conditional on having any nonzero transactions (one of the auxiliary questions on the checklist; note that most items on the checklist cannot be meaningfully completed if no relevant transactions took place over the previous week), we compare the checklist scores in the Social Recognition arm to those in the Control arm. ${ }^{4}$ For completeness, we first display the results pooled across the two states in Table 3A, then in Table 3B our main focus: disaggregated by state. A visualization of those trends in both states is provided in Fig. 2 (upper and lower panels, respectively; "Week 0" indicates baseline performance prior to the start of the experiment).

As shown in Table $3 \mathrm{~B},{ }^{5}$ Social Recognition-having a Certificate of Excellence displaying the facility's performance in public on a weekly basis + public ceremony for top performer at the conclusion of the trial -improved the checklist score by 12.4 percentage points in Ekiti State: a roughly 18-percent increase over baseline. The p-value for this effect is 0.005. In Niger State, however, there was no detectable effect of the Social Recognition intervention. ${ }^{6}$

To be sure that the results are not sensitive to our choice of the simplest possible specification, we provide three alternative empirical specifications in Table 3B. The specification in the first and fifth columns is straightforward:

$Y_{i t}=\beta^{1}{ }_{\text {social }}$ Social $_{i t}+\gamma^{1}{ }_{L G A}+\varepsilon^{1}{ }_{i t}$

The outcome, $Y_{i b}$ is the score on the record-keeping checklist; the main right-hand-side variable is Social $_{i t}$, an indicator for whether facility $i$ is exposed (by the randomization) to the social recognition intervention in period $t$. For facilities assigned to treatment, this is 1 for periods $1-4$, and 0 only in baseline period zero (which we do not use in our initial specification); for facilities assigned to comparison, this is 0 throughout. Because treatment was randomized within "Local Government Authority," or "LGA," we include fixed effects for these strata. (We also use this specification in the first column of Table 3A, including an interaction between Social $_{i t}$ and an indicator for Ekiti state, Ekiti $i_{i}$ in the second column of Table 3A.) In the second (and sixth) column of Table 3B, we also add the facility's score in the week prior to intervention (i.e. baseline performance in period 0) as a control variable. Doing so increases precision slightly, but does not substantially change the main coefficient estimate. (Analogously in Table 3A, columns 3 and 4.) In the third (and seventh) column of Table $3 B$, we include data from the week prior to intervention (baseline period zero) to estimate a difference-in-differences model:

$Y_{i t}=\beta^{2}{ }_{\text {social }}$ Social $_{i t}+\gamma^{2}{ }_{i}+\varepsilon^{2}{ }_{i t}$

As is shown in Eq. (2), we include facility fixed effects rather than simply LGA fixed effects. This yields a higher point estimate, but with slightly wider standard errors. (Analogously in Table 3A, columns 5 and 6.) Finally, in the fourth (and eighth) column of Table 3B (and analogously in the last columns of Table $3 \mathrm{~A}$ ), we use the difference-in-difference specification of Eq. (2), but also include scores from weeks when there were no relevant transactions at the facility. While this mutes the effect somewhat, the coefficient remains statistically

\footnotetext{
${ }^{4}$ Nonzero transactions are present in 80 percent of facility-weeks. The fraction of weeks (out of four) that a given facility has nonzero transactions varies from zero to one; the distribution is shown in Appendix Fig. A6.

${ }^{5}$ Note that the pooled results presented in Table 3A (odd numbered columns) vary based on the specification. We interpret this as inconclusive and do not claim that there is an overall effect of social recognition across both states.

${ }^{6}$ We have just one main outcome, but two states in which we test the intervention's effects on it. With an unadjusted p-value of 0.005 , our finding is robust to the Dunn/Bonferroni multiple test correction (in its simplest form, multiplying the p-value by the number of tests), which yields an adjusted pvalue of approximately 0.01 .
}

significant. ${ }^{7}$ Except for the baseline week score included in columns 2 and 6 , no baseline covariate is included in any other specification in Table 3B. Because the logarithm of the number of outpatients was unbalanced across treatment arms in Ekiti, we include it as a control in regressions in Appendix Table A3. The pattern of results, in terms of magnitude as well as statistical significance, remains unchanged. Table 3A, corroborating the patterns in Table 3B (through only slightly different specifications, as described above), shows an interaction between the Ekiti indicator and the social recognition treatment that is positive and significant in three of four specifications ( $p<0.01$ in two cases; $\mathrm{p}<0.05$ in one case).

The outcome throughout Tables $3 \mathrm{~A}$ and $3 \mathrm{~B}$ is a scoring scale that runs from a minimum percentage score of zero to a maximum of one. While the "score" on the checklist is the basis for the Social Recognition incentive, on its own it may not translate or compare meaningfully to other contexts; underlying behaviors may translate better. To clarify this, the impact in Ekiti can be broken down into effects on each of the ten key components of the score, as shown in Fig. 3.

As can be seen in Fig. 3, Social Recognition motivated staff in Ekiti to complete all sections of the forms, to do so prior to enumerator arrival, and to check the forms for their accuracy and completeness. These changes on the first seven checklist items are all near 20 percentage points, which in some cases is a very large fraction of the Control group value: only half of the Control group facilities, for example, had the form checked by the treasurer or officer-in-charge prior to the enumerator's weekly visit.

The Social Recognition intervention, however effective at encouraging staff to complete the cash book form, did not change the likelihood that documentation was available to substantiate the sections of the form that pertained to cash receipts. It also did not change the likelihood that the different forms relating to drug acquisition agreed with one another, though the Control group already performed relatively well on this particular component of record keeping. This may have occurred because while record keeping officers were themselves able to enhance completeness and accuracy of the records, documentation of cash receipts and drugs also relied on the participation of other health workers in the facilities.

The bulk of the analysis shown here is conditional on nonzero transaction data: that is, that there is any information to record in the cash book form, and thus for which the checklist can assess completeness and accuracy. Any changes in the rates of nonzero transaction data that are induced by the intervention could pose a potential threat to validity. In Appendix Table A1, we test for changes in the rates of nonzero transaction data on the cash book form in both states, and find no significant difference between experimental study arms.

\subsection{Heterogeneity}

We explore the hypothesis that the difference in treatment effect is driven by facility-level differences rather than a different managerial environment at the state level. In Table 4, we consider a range of dimensions from Table 1 along which our contexts in Ekiti and Niger saliently differ and that could plausibly interact with the Social Recognition treatment. The expected direction of their effects may depend on various psychological and behavioral mechanisms and assumptions. For example, busier staff could be more responsive to the treatment if the recognition is salient as time scarcity makes staff focus on short term outcomes (Mullainathan \& Shafir, 2013), or they could be less responsive if the payoff from the intervention is construed as to be career benefits whose temporal distance leads them to be heavily discounted. Having more women on staff or as patients could decrease the effect of the Social Recognition intervention if women compete less for this recognition than men do (Andersen et al., 2013), or it could make

\footnotetext{
${ }^{7}$ Note that $R^{2}$ is lower in columns $1,2,5$, and 6, and higher in columns 3, 4, 7, and 8 . This is because, as shown in Equation (2), facility fixed effects absorb a large amount of variation.
} 
Table 3A

Main effects, pooled across states.

\begin{tabular}{|c|c|c|c|c|c|c|c|c|}
\hline & [1] & {$[2]$} & [3] & [4] & [5] & [6] & [7] & {$[8]$} \\
\hline Social recognition & $\begin{array}{l}0.032 \\
(0.025)\end{array}$ & $\begin{array}{l}-0.020 \\
(0.027)\end{array}$ & $\begin{array}{l}0.034 \\
(0.022)\end{array}$ & $\begin{array}{l}-0.009 \\
(0.025)\end{array}$ & $\begin{array}{l}0.091 * * \\
(0.035)\end{array}$ & $\begin{array}{l}0.014 \\
(0.03)\end{array}$ & $\begin{array}{l}0.081 * * \\
(0.032)\end{array}$ & $\begin{array}{l}0.054 \\
(0.039)\end{array}$ \\
\hline Social recognition $\times$ Ekiti & & $\begin{array}{l}0.144^{* * *} \\
(0.051)\end{array}$ & & $\begin{array}{l}0.114^{* * *} \\
(0.025)\end{array}$ & & $\begin{array}{l}0.176^{* *} \\
(0.03)\end{array}$ & & $\begin{array}{l}0.055 \\
(0.039)\end{array}$ \\
\hline Baseline score & & & $\begin{array}{l}0.318^{* * *} \\
(0.087)\end{array}$ & $\begin{array}{l}0.290^{* * *} \\
(0.084)\end{array}$ & & & & \\
\hline Constant & $\begin{array}{l}0.681^{* * *} \\
(0.017)\end{array}$ & $\begin{array}{l}0.679 * * * \\
(0.017)\end{array}$ & $\begin{array}{l}0.477^{* * *} \\
(0.057)\end{array}$ & $\begin{array}{l}0.493^{* * *} \\
(0.054)\end{array}$ & $\begin{array}{l}0.650 * * * \\
(0.014)\end{array}$ & $\begin{array}{l}0.653^{* * *} \\
(0.012)\end{array}$ & $\begin{array}{l}0.671 * * * \\
(0.013)\end{array}$ & $\begin{array}{l}0.671 * * * \\
(0.013)\end{array}$ \\
\hline $\mathrm{R}^{2}$ & 0.326 & 0.349 & 0.396 & 0.410 & 0.625 & 0.635 & 0.578 & 0.579 \\
\hline F test & & 4.325 & & 4.646 & & 4.986 & & 3.191 \\
\hline $\mathrm{p}$-value from $\mathrm{F}$ test & & 0.0152 & & 0.0113 & & 0.0082 & & 0.0441 \\
\hline Observations & 459 & 459 & 451 & 451 & 558 & 558 & 696 & 696 \\
\hline
\end{tabular}

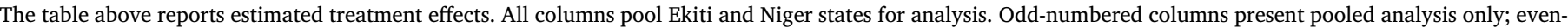

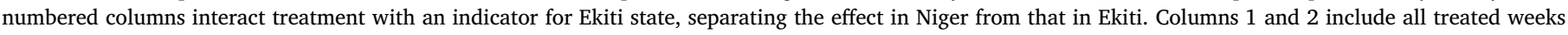

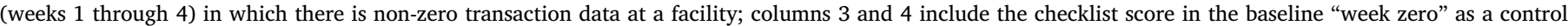

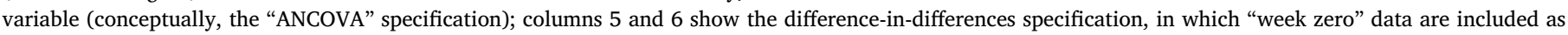

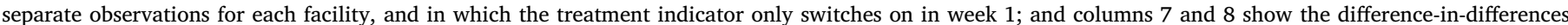

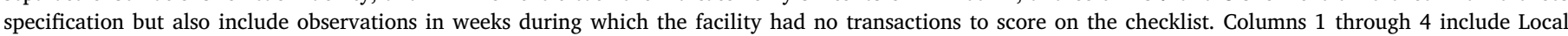

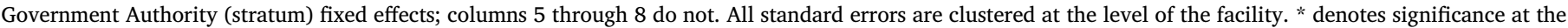
$10 \%$ level, $* *$ at the $5 \%$ level, and $* * *$ at the $1 \%$ level.

Table 3B

Main effects.

\begin{tabular}{|c|c|c|c|c|c|c|c|c|}
\hline & \multicolumn{4}{|l|}{ Ekiti } & \multicolumn{4}{|l|}{ Niger } \\
\hline & [1] & {$[2]$} & [3] & [4] & {$[5]$} & {$[6]$} & [7] & {$[8]$} \\
\hline Social recognition & $\begin{array}{l}0.124 * * * \\
(0.044)\end{array}$ & $\begin{array}{l}0.104^{* * *} \\
(0.035)\end{array}$ & $\begin{array}{l}0.190^{* * *} \\
(0.062)\end{array}$ & $\begin{array}{l}0.110^{* *} \\
(0.052)\end{array}$ & $\begin{array}{l}-0.020 \\
(0.028)\end{array}$ & $\begin{array}{c}-0.011 \\
(0.023)\end{array}$ & $\begin{array}{l}0.014 \\
(0.030)\end{array}$ & $\begin{array}{l}0.054 \\
(0.039)\end{array}$ \\
\hline Baseline score & & $\begin{array}{l}0.304^{* * *} \\
(0.092)\end{array}$ & & & & $\begin{array}{l}0.261 \\
(0.177)\end{array}$ & & \\
\hline Constant & $\begin{array}{l}0.742^{* * *} \\
(0.033)\end{array}$ & $\begin{array}{l}0.542^{* * *} \\
(0.071)\end{array}$ & $\begin{array}{l}0.702 * * * \\
(0.024)\end{array}$ & $\begin{array}{l}0.735 * * * \\
(0.021)\end{array}$ & $\begin{array}{l}0.638^{* * *} \\
(0.018)\end{array}$ & $\begin{array}{l}0.472^{* * *} \\
(0.105)\end{array}$ & $\begin{array}{l}0.619^{* * *} \\
(0.012)\end{array}$ & $\begin{array}{l}0.615^{* * *} \\
(0.015)\end{array}$ \\
\hline $\mathrm{R}^{2}$ & 0.221 & 0.289 & 0.574 & 0.545 & 0.257 & 0.324 & 0.62 & 0.519 \\
\hline Observations & 182 & 182 & 228 & 323 & 277 & 269 & 330 & 373 \\
\hline
\end{tabular}

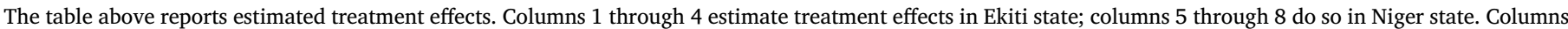

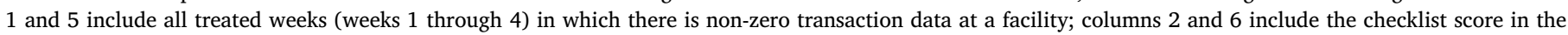

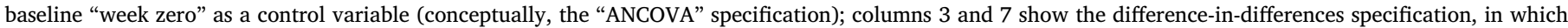

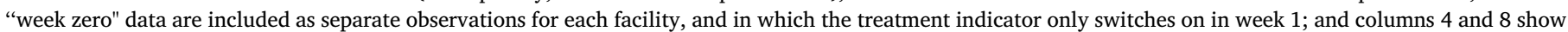

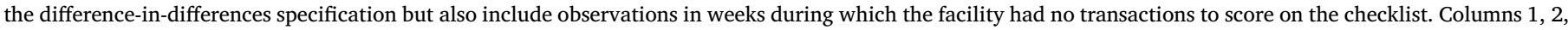

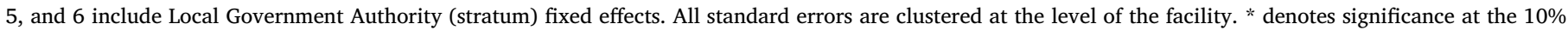
level, $* *$ at the $5 \%$ level, and $* * *$ at the $1 \%$ level.

the treatment more effective because women may be more pro-social than men (Eckel \& Grossman, 1998). More educated patients could either make the treatment more effective because such patients are more likely to understand what the Certificate of Excellence stands for and react to it, or could make the treatment less effective if more socioeconomically advantaged populations-perhaps both patients and providers-prove less likely to respond to the certificate because they are less pro-social (Piff, Kraus, Côté, Cheng, \& Keltner, 2010). Having staff exclusively dedicated to accounting at a PHC facility could increase the effect of the social recognition intervention, especially if healthcare workers care about what that staff member thinks, or having such staff members could reduce the effect of social recognition because working hard on this could be seen as suggesting that the accounting staff was previously ineffective. And the number of staff listed on the roster could increase the effectiveness of social recognition - a larger number of peers could increase the pressure on staff to perform and attain recognition - but it could also conceivably reduce the effect of social recognition because it could make it easier for responsibility to become diffuse through a bystander effect (Chekroun \& Brauer, 2002).

Accordingly, in Table 4 we show results from a series of tests. In each row of the table, Columns 1 and 2 report coefficients and p-values from estimation of an equation of the form:

$Y_{i t}=\beta^{3}{ }_{\text {social }}$ Social $_{i t}+\beta^{3}{ }_{\text {direct }} X_{i}+\beta^{3}{ }_{\text {interaction }}$ Social $_{i t} \cdot X_{i}+\gamma^{3}{ }_{L G A}+\varepsilon^{3}{ }_{i t}$

In each row, we report tests of whether a single covariate, $X_{i}$, has a direct effect, predicting the levels of the main outcome $\left(\beta_{\text {direct }}^{3}\right)$, or an interaction with the social recognition treatment, predicting 

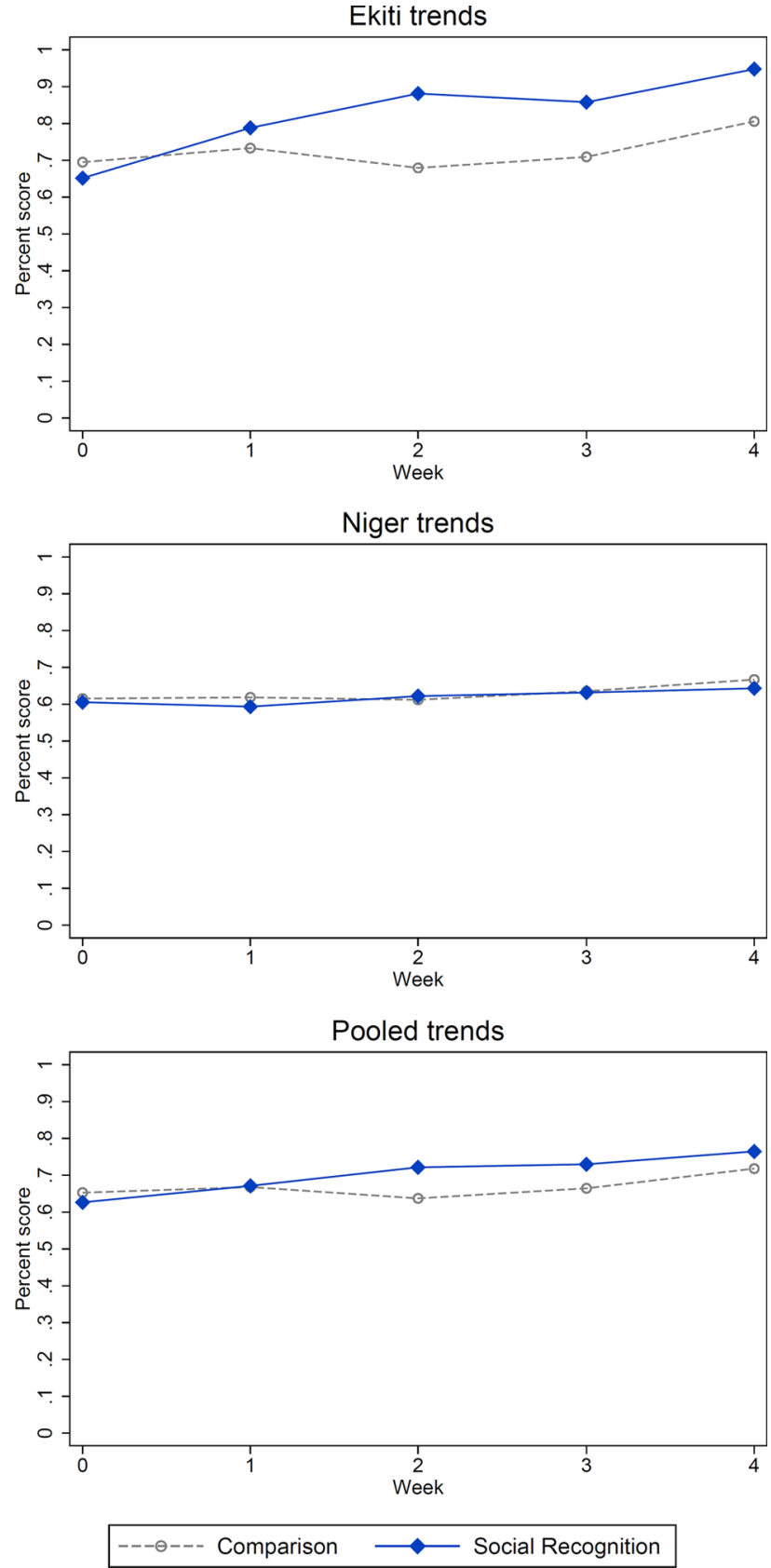

Fig. 2. Record-keeping checklist score over time. In the figures above, average scores on the record-keeping checklist (where 1.0 is the maximum score) are plotted over time, conditional on having nonzero transactions to report on the checklist in each week. The upper panels show each state separately; the last panel pools both states.

heterogeneity in treatment effects $\left(\beta_{\text {interaction }}^{3}\right)$, taking data from both states pooled. The estimation also includes local government authority (LGA) fixed effects $\left(\gamma_{L G A}\right)$ because these were the geographic strata within which treatment was randomized. Columns 3 and 4 provide analogous reporting but with the sample restricted to Ekiti only. For clarity, we rewrite the equation above, replacing the superscript " 3 " with a superscript "4" for estimation within Ekiti, although the specification is the same:

$Y_{i t}=\beta_{\text {social }}^{4}$ Social $_{i t}+\beta_{\text {direct }}^{4} X_{i}+\beta^{4}{ }_{\text {interaction }}$ Social $_{i t} \cdot X_{i}+\gamma^{4}{ }_{L G A}+\varepsilon^{4}{ }_{i t}$
Finally, Column 5 reports the state-treatment interaction term after inclusion of the covariate, $X_{i}$, and its interaction with the social recognition treatment. This column estimates the following equation with data from both states:

$$
\begin{aligned}
Y_{i t}= & \beta_{\text {social }}^{5} \text { Social }_{\text {it }}+\beta_{\text {direct }}^{5} X_{i}+\beta_{\text {interaction }}^{5} \text { Social }_{i t} \cdot X_{i}+\beta_{\text {state-treatment }}^{5} \\
& \text { Social }_{i t} \cdot \text { Ekiti }_{i}+\gamma_{L G A}^{5}+\varepsilon_{i t}^{5}
\end{aligned}
$$

The coefficient reported in Column 5 of the table is the estimate of $\beta_{\text {state-treatment }}^{5}$ which quantifies the difference between social recognition treatment effects in Ekiti and Niger. Without any inclusion of covariates, this would be the difference between coefficients reported in Columns 1 and 5 of Table 3B, or roughly 0.14 .

Taking the first row of Table 4, for example, Columns 1 and 2 show that the logarithm of the number of patients seen monthly (the covariate used as $X_{i}$ in this row) is not predictive of a facility's level of performance in maintaining records, nor is it predictive of the effect of the social recognition intervention (both the direct association and the interaction are estimated to be very small in magnitude and neither is statistically significant). Columns 3 and 4 confirm that this is also true when restricting attention to Ekiti. Column 5 shows an estimate of 0.15 in the first row (almost unchanged from 0.14), showing that the inclusion of this covariate did not explain the difference in treatment effects across states.

As can be seen in columns 1 and 2, though two of the covariates are associated with performance (i.e. checklist score) at the 5 percent level, and two more are significant at the 10 percent level, only one-fraction female among staff-has a statistically significant association with variation in treatment effects (columns 3 and 4), and it does not explain any of the difference in treatment effects between Ekiti and Niger (columns 5 and 6). The two covariates whose inclusion diminishes the statistical significance of the difference between the states, number of days open per week and staff for financial accounting, have neither a statistically significant association with performance nor are predictive of treatment effect heterogeneity in Ekiti, and neither drives the point estimate of the difference in treatment effects between states to zero. Finally, we neither observe heterogeneity in treatment effect with population density (which is significantly higher in Ekiti), nor with respect to distance to the nearest other health facility in that state, either of which could have affected communication between facilities and communities thereby influencing the effectiveness of our treatment. To corroborate this, we use the LASSO (as implemented by Ahrens, Hansen, \& Schaffer, 2018) to select variables in a pooled regression of the outcome on possible (standardized) covariates and interactions with the social recognition treatment, collapsing the dataset so that there is only one observation per facility. Results, shown in Appendix Table A5, always select the interaction of the indicator for Ekiti state and the social recognition treatment, but never the interaction of any other covariate with the social recognition treatment.

In short, our observable attributes at the facility level are unable to explain why the treatment had significant effects in Ekiti but not in Niger. This finding may suggest the importance of institutional, managerial, and perhaps even behavioral variables that are not routinely collected in surveys.

\section{Conclusion}

In this paper we provide quantitative experimental evidence regarding the effect of an incentive designed to encourage bureaucrats to perform better at work. Specifically, we introduced a public social incentive intervention for accounting staff in health facilities over a 4-week period in two Nigerian states, Ekiti and Niger, and tested its effect on how well they tracked their resources. As has been shown, despite being part of the same country and despite parallel program implementation through the same organization, the two states exhibited substantially divergent results.

The social recognition intervention had a nontrivial and statistically 
Had facility staff completely filled Cash Book Form before you arrived? $0.219=39.6$ pct of 0.552

Did OIC/Treasurer check Cash Book Form for inaccuracies and incompleteness? $0.182=29.9$ pct of 0.609

Fraction of days: Balance Forward section complete $0.201=27.7$ pct of 0.725

Fraction of days: Cash Receipts from User Charges section complete $0.178=25.6$ pct of 0.695

Fraction of days: Cash Receipts from Drug Sales section complete $0.180=25.7$ pct of 0.699

Fraction of days: Expenditure section complete $0.202=30.1$ pct of 0.672

Fraction of days: Expenditure from Drug Sales section complete $0.204=32.2$ pct of 0.633

Cash Book Form consistent with Drug Supplies and Purchases Form $0.029=3.1$ pet of 0.947

Documentation to substantiate data for cash receipts from user charges $0.059=7.1$ pct of 0.834

Documentation to substantiate data for cash receipts from expenditure $0.075=10.7$ pct of 0.705

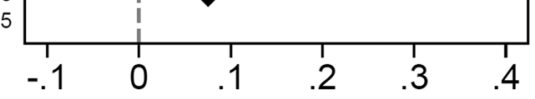

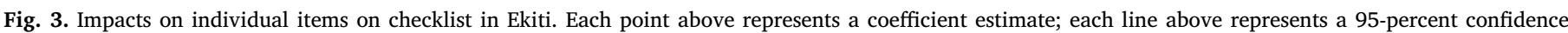

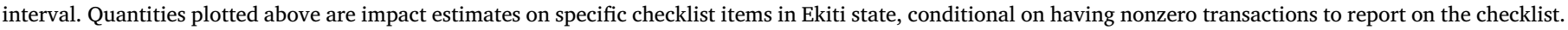

Table 4

Interactions.

$\begin{array}{llll}\text { Both states } & & & \\ \beta_{\text {direct }}^{1} & \beta_{\text {interaction }}^{1} & \text { Ekiti } & \beta_{\text {interaction }}^{2} \\ \text { Direct effect of covariate } & \text { Interacted covariate } & \text { Direct effect of covariate } & \text { Interacted covariate } \\ (1) & (2) & (3) & \text { (4) }\end{array}$

\begin{tabular}{|c|c|c|c|c|c|c|c|c|c|c|}
\hline \multicolumn{11}{|l|}{ Patients: } \\
\hline Log(patients) & 0.04 & $\mathrm{p}=0.151$ & -0.02 & $\mathrm{p}=0.520$ & 0.03 & $\mathrm{p}=0.498$ & -0.03 & $\mathrm{p}=0.584$ & $0.15^{* * *}$ & $\mathrm{p}=0.009$ \\
\hline Gender ratio & 0.00 & $\mathrm{p}=0.881$ & 0.03 & $\mathrm{p}=0.363$ & 0.02 & $\mathrm{p}=0.590$ & -0.01 & $\mathrm{p}=0.863$ & $0.16 * * *$ & $\mathrm{p}=0.004$ \\
\hline Education & 0.02 & $\mathrm{p}=0.385$ & $0.04 *$ & $\mathrm{p}=0.078$ & $0.10 *$ & $\mathrm{p}=0.063$ & 0.01 & $\mathrm{p}=0.828$ & $0.12^{* *}$ & $\mathrm{p}=0.024$ \\
\hline Pop. density & . & . & -0.00 & $\mathrm{p}=0.917$ & . & . & 0.05 & $\mathrm{p}=0.510$ & $0.15^{* * *}$ & $\mathrm{p}=0.005$ \\
\hline \multicolumn{11}{|c|}{ Operational characteristics: } \\
\hline Days open & $0.05^{*}$ & $\mathrm{p}=0.057$ & 0.03 & $\mathrm{p}=0.245$ & 0.06 & $\mathrm{p}=0.173$ & -0.01 & $\mathrm{p}=0.913$ & $0.12^{*}$ & $\mathrm{p}=0.080$ \\
\hline Hours open & 0.03 & $\mathrm{p}=0.263$ & 0.03 & $\mathrm{p}=0.301$ & $0.07^{* *}$ & $\mathrm{p}=0.043$ & -0.02 & $\mathrm{p}=0.707$ & $0.20^{* *}$ & $\mathrm{p}=0.013$ \\
\hline Baseline score & $0.08^{* * *}$ & $\mathrm{p}=0.004$ & 0.00 & $\mathrm{p}=0.940$ & $0.08^{* * *}$ & $\mathrm{p}=0.001$ & -0.03 & $\mathrm{p}=0.375$ & $0.12^{* * *}$ & $\mathrm{p}=0.006$ \\
\hline KM to neighbor & $0.06^{* *}$ & $\mathrm{p}=0.040$ & $-0.04 *$ & $\mathrm{p}=0.050$ & -0.09 & $\mathrm{p}=0.600$ & 0.12 & $\mathrm{p}=0.588$ & $0.15^{* * *}$ & $\mathrm{p}=0.008$ \\
\hline \multicolumn{11}{|l|}{ Staff: } \\
\hline Accounting & $0.05^{* *}$ & $\mathrm{p}=0.013$ & $0.06^{* *}$ & $\mathrm{p}=0.024$ & 0.04 & $\mathrm{p}=0.434$ & 0.07 & $\mathrm{p}=0.194$ & 0.07 & $\mathrm{p}=0.323$ \\
\hline Total staff & 0.02 & $\mathrm{p}=0.558$ & 0.03 & $\mathrm{p}=0.311$ & $0.07^{*}$ & $\mathrm{p}=0.093$ & -0.03 & $\mathrm{p}=0.487$ & $0.14^{* * *}$ & $\mathrm{p}=0.044$ \\
\hline Fraction female & -0.00 & $\mathrm{p}=0.919$ & $0.04^{* *}$ & $\mathrm{p}=0.035$ & $0.22^{* *}$ & $\mathrm{p}=0.036$ & $-0.31^{* *}$ & $\mathrm{p}=0.015$ & $0.15^{* * *}$ & $\mathrm{p}=0.026$ \\
\hline
\end{tabular}

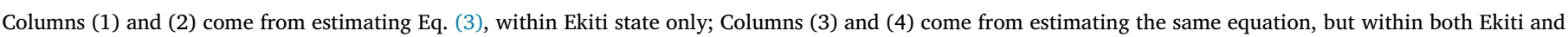

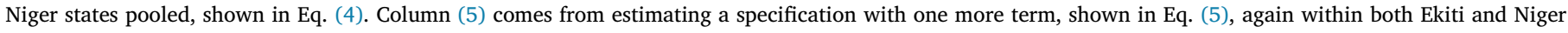

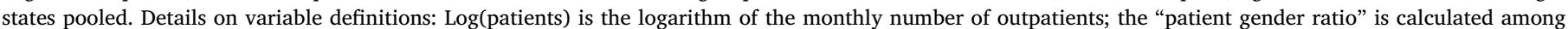

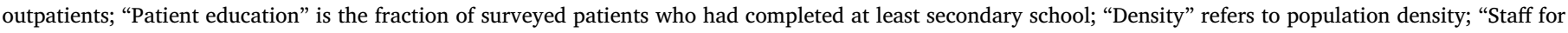
accounting" is an indicator for whether each facility has a specific staff member tasked with financial accounting.

significant positive impact on performance in Ekiti but essentially no effect in Niger. The positive outcome in Ekiti was seen across multiple sub-dimensions, especially regarding completeness of the target cash book form, with less effect on the existence of substantiating documentation. Though the intervention we study was not itself intended to be an exact replication of any other intervention, it closely resembles the format of other social recognition interventions (in this case, combining visual "stars" with a public ceremony for recognition, similarly to Ashraf et al., 2014). Our 
study results may be seen as corroborating evidence that social recognition can have substantial-though heterogeneous-effects. ${ }^{8}$

That we find a difference in effects across states both adds a layer of complication, and connects this work to a wider literature on external validity. Our quantitative analyses strongly suggest that contextual factors at state, community and facility levels may play a key role in determining the viability and effectiveness of our interventions in particular facilities. Recent work shows that the same intervention can have different effects in the hands of different implementers - a regularity across low-, middle-, and high-income countries (Bold et al., 2013; Banerjee, Karlan, \& Zinman, 2015; Allcott, 2015). Others have shown that the same intervention can have different effects at different times (Rosenzweig and Udry 2016). The present project attempted to test for contextual factors while keeping the implementer and timing constant. ${ }^{9}$ Ours is also not the first study to find different treatment effects in different locations: Kremer, Miguel, and Thornton (2009), for example, found strong effects of a merit scholarship program in one Kenyan district but not in another. However, there were immediate signs of differential program behavior in their case: for example, of the 127 facilities they study, spread across two districts, five immediately quit the study following a lightning strike in one district while only one facility left the study in the other district. We saw no such obvious outward sign of differential program reception: none of the 140 facilities dropped out of our study in either state.

Our analysis found that the reason for the heterogeneous effects between the two states is not explained by facility-level variables of the kind usually collected in field surveys, including measures of human capital and facility-level productivity. Explaining heterogeneity and assessing external validity of social recognition interventions may require the collection of new kinds of data both at the individual staff level (e.g., social preferences, time discounting) and at the firm/ministry level (e.g., institutional or professional incentives including career dynamics, supervision structures, accountability). Consistent with Kremer and Glennerster (2011) suggestion that the success of interventions in health systems may depend on institutional context, we speculate that the availability of institutional, psychological, and cultural variables might help pin down the mechanism through which social recognition may operate in a given context (e.g., comparison to peers, principal-agent concerns, a gift relationship between employers and employees, the concerns of patients and customers, and reputation effects). ${ }^{10}$ Future work could help distinguish these potential pathways as a function of the population and environment.

What we can say is that the RCT took place in two states that are very different in terms of human capital and bureaucratic organization. Across several indicators, Ekiti exhibits higher capacity than Niger, in terms of both aspects (Table 1). In addition, figures from the 2013 Demographic and Health Survey (DHS), such as data on birth registration rates, suggest that there is more bureaucratic capacity in Ekiti.

\footnotetext{
${ }^{8} \mathrm{~A}$ similar finding across multiple studies makes it more likely that the finding is not a false positive. This is pointed out by Maniadis, Tufano, and List (2014) in relation to recent laboratory experiments in economics. Relatedly, it is the general intent of meta-analysis and systematic review to aggregate patterns across studies, improving precision and understanding; this of course can only be done once there are multiple studies to aggregate (Hunt, 1997; Petticrew \& Roberts, 2008). The present study would only qualify as a replication in the third and weakest sense described by Levitt and List (2009), however, since it addresses the same general hypothesis as others have previously, but with a different experimental design, context, and so on.

${ }^{9}$ Note that the intervention is carried out by the same implementer (certificates were scored and posted by the same non-government firm) in the two states, but that the health centers themselves are managed by each state government's independent health agency.

${ }^{10}$ Qualitative work that accompanied our experiment suggests that the social recognition certificates did not grab the attention of many patients, and that pride or shame in front of peers may have been a more active mechanism.
}

This suggests, tentatively, that the social recognition incentive requires higher levels of training and organization on the part of higher-level public sector health officials in order to be effective. It may be that social recognition was motivating for officials in Ekiti, but not Niger, because in Ekiti healthcare workers believed that the bureaucracy had the capacity to use social recognition as a credible input into long-term career incentives. Indeed, qualitative interviews conducted alongside our experiment suggested that Ekiti staff rotate more often than Niger staff. Social recognition might be more valuable in contexts in which staff are pursuing new positions.

Niger and Ekiti states also differ along many other dimensions; in addition to the many demographic differences enumerated in this paper, the drug procurement systems for the public health systems in the two states depend on different fractions of public funding; selling drugs on credit, which makes bookkeeping more complex, also appears to be more widespread in Niger (Gauthier, Pimhidzai, and Saleh 2018, Chapter 5). As in many developing countries, the bureaucratic and managerial environment for service providers in Nigeria is highly heterogeneous, with variation between states and even within a single state (Rogger, 2017). That an intervention was successful in one state, but not another, speaks to the importance of considering this variation when translating successful findings to a new context-even when the implementers in both cases are the same.

It is noteworthy that the control group in Ekiti increased performance over the study period (see Fig. 2). This suggestive upward trend may have been due to unrelated external factors, training (i.e. learning about how to fill out the forms correctly), spillovers from the Social Recognition arm, or the mere fact of being monitored. The last would be consistent with work finding that doctors improve their performance when peers simply inquire about their work (Brock, Lange, and Leonard, 2016) and suggests that even light-touch interventions, such as phone calls or texts from peers, could be effective for improving bureaucratic performance in developing countries. Consistent with the transparency and decentralization literature (Gonçalves, 2014; Bardhan, 2016; Gauri et al., 2015; Olken, 2007; Björkman and Svensson, 2009), this also suggests that observation from the public may matter. Indeed, the broader role of community engagement to improve performance is ripe for further exploration.

In Ekiti, the Social Recognition intervention significantly improved the quality with which facilities filled out the cash book form and sustained the improved performance over the intervention period. Naturally, this analysis cannot tell us anything about long-term effects of similar approaches, and in particular whether there is potentially either adaptation to the recognition or, on the flipside, habit formation, regarding the desired activity.

Finally, it would be valuable to know more about the effects of our intervention on the overall performance of the PHC staff in a multi-task environment. For example, our measured increase in record keeping performance may have come at the cost of other tasks the staff was also responsible for (Holmstrom \& Milgrom, 1991). While such an analysis may be empirically difficult to operationalize when one doesn't know where to look for potential spill-over effects, we explored the effect on two other performance indicators that seemed potentially likely: patient wait times and treatment times; we did not find evidence for these kinds of externalities (see Appendix Table A4).

Future work may further explore the external validity of interventions in organizational contexts and light touch ways of improving bureaucracies in developing countries.

\section{Acknowledgement}

The authors gratefully acknowledge the contributions of Ghazia Aslam, Iman Hafiz, Obert Pimhidzai, Shomikho Raha, Karima Saleh, Temilade Sesan; and Iman Sen and Egon Tripodi for research support. We also thank David Evans, Anne Fitzpatrick, Rachel Glennerster, Pamela Jakiela, Oyebola Okunogbe, Dan Rogger, and audiences at UC 
Berkeley/CEGA, the University of Pennsylvania, Oxford/CSAE, the Baltic Economic Association meeting in Vilnius, the Behavioral / Experimental Health Economics meeting in Oslo, and the Paris School of Economics for helpful comments on earlier drafts. This field trial of social recognition was part of a larger study undertaken by Saleh, from the World Bank, described in Gauthier, Pimhidzai and Saleh. 2018. "Resource Tracking in Primary Health Care in Nigeria: Case Study from Niger and Ekiti states," Vol I and II, World Bank, Washington, D.C. This

Appendix A:. Scoring checklist questions assessing quality of records study is registered with the AEA RCT registry (socialscienceregistry.org), number AEARCTR-0002763. The findings and views expressed in this paper do not necessarily represent those of the World Bank, its Executive Directors, or the governments of the countries they represent.

\section{Declaration of Competing Interests}

None.

\section{Introductory question}

1. Is the cash book form kept in the facility?

\section{Auxiliary questions}

1. Number of days in this week the facility is open

2. Are all entries on cash book form zero?

Main questions:

1. Prior to arrival:

Had the facility staff completely filled the cash book form before you arrived?

2. Treasurer/Officer-In-Charge (OIC) check:

Did Facility OIC/Treasurer check cash book form for inaccuracies and incompleteness?

3-7: Completeness on each day. For how many days

3 . is the 'Balance forward' section of cash book form complete?

4. is the 'Cash receipts from user charges' section of cash book form complete?

5 . is the 'Cash receipts from drug sales' section of cash book form complete?

6. is the 'Expenditure' section of cash book form complete?

7. is the 'Expenditure from drug sales' section of cash book form complete?

8. Consistency Cross-Check:

Are the drug purchases and sales records appearing on cash book form consistent with the drug purchases and sales records appearing on the drug supplies and purchases form? (See Figs. A1-A6).

9-10. Documentation. Can the staff provide receipts/invoices or other documentation

9. to substantiate the data for cash receipts from user charges?

10. to substantiate the data for cash receipts from expenditure? (See Tables A1-A5).

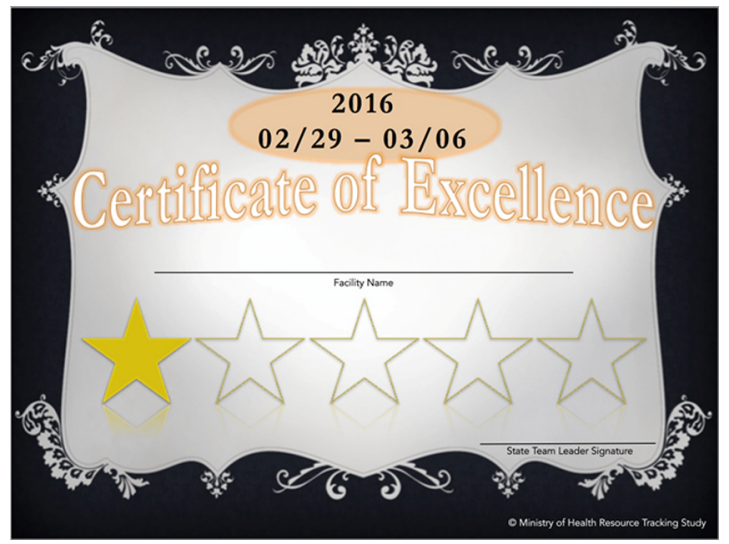

Fig. A1. Appendix figure of certificate. 


\section{Fraction of Women with No Formal Schooling (DHS 2013)}

100

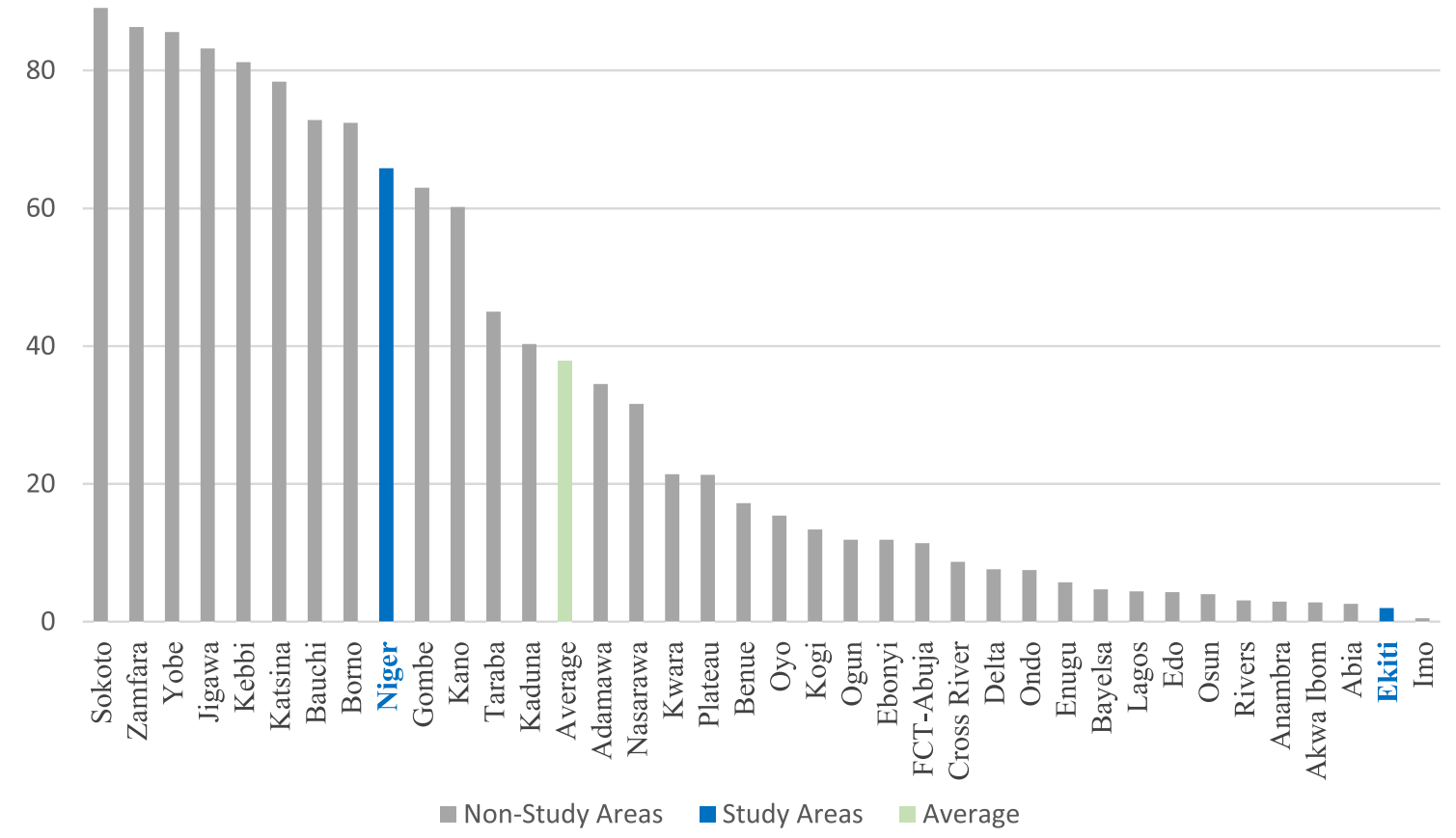

Fig. A2. Appendix figure on DHS differences. The bars above show the relative positions of Ekiti and Niger in the distribution of states in Nigeria according to the educational attainment of women.

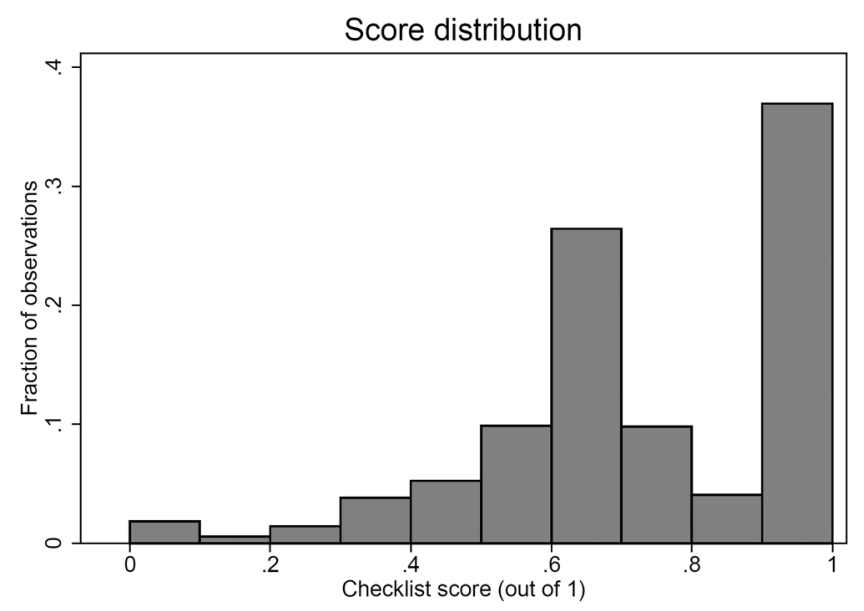

Fig. A3. Appendix figure on score distribution. 

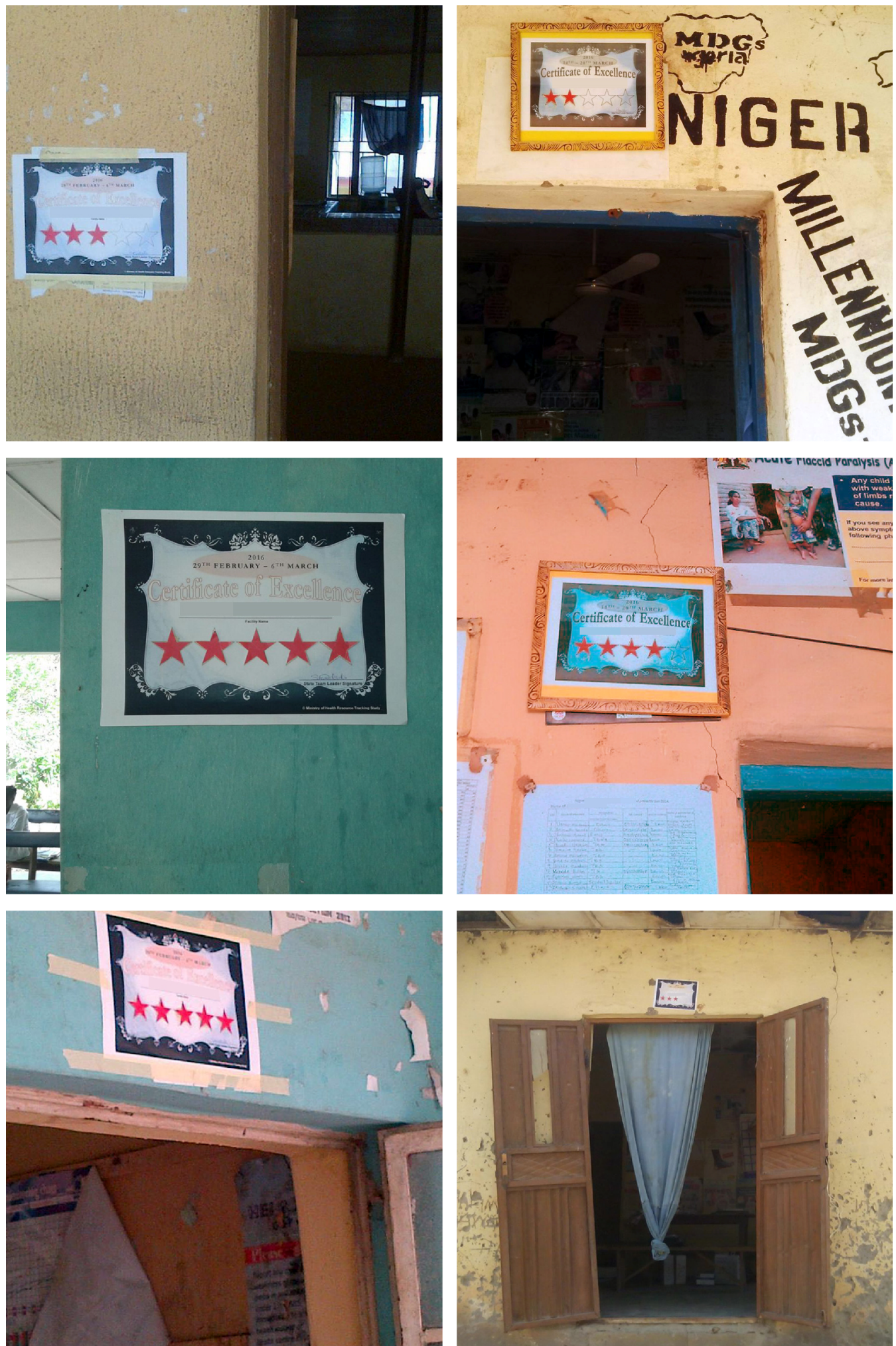

Fig. A4. Appendix figure on display of certificates. 


\section{Ekiti and Niger}

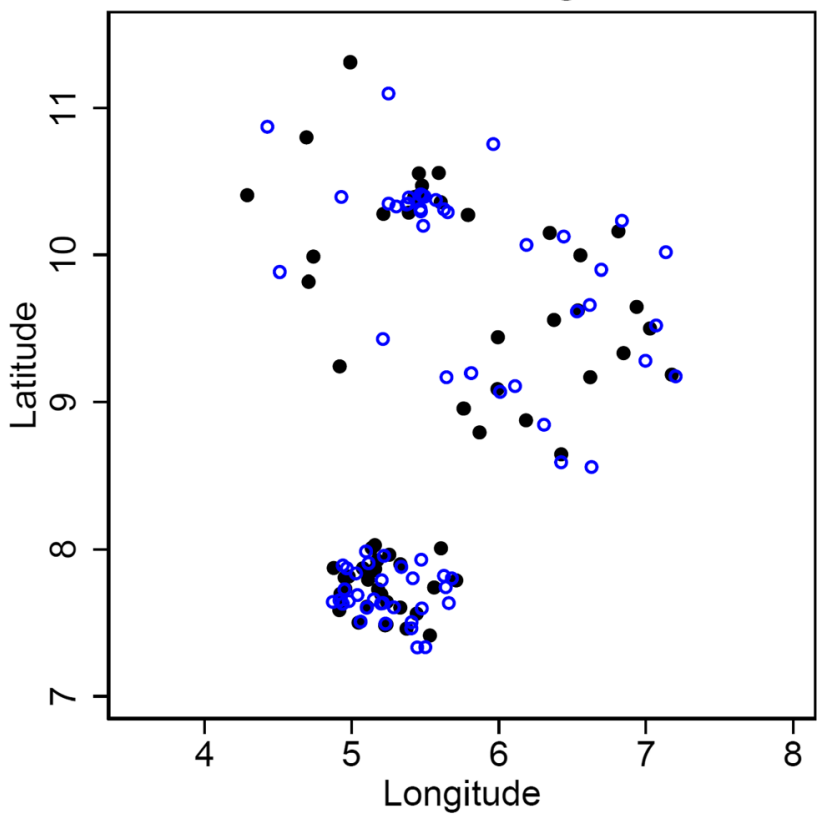

- Treatment $\circ$ Control

Fig. A5. Geography of sites by study arm.

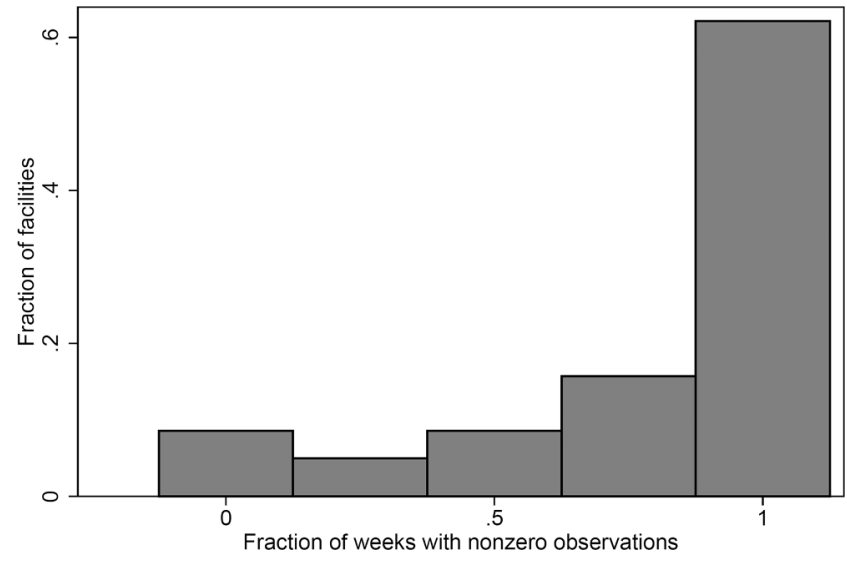

Fig. A6. Nonzero transaction distribution. 
Table A1

Appendix table: Effects on likelihood of nonzero transactions, by state.

\begin{tabular}{lll} 
& $\begin{array}{l}\text { Ekiti } \\
{[1]}\end{array}$ & $\begin{array}{l}\text { Niger } \\
{[2]}\end{array}$ \\
\hline Social recognition & -0.034 & -0.014 \\
& $(0.085)$ & $(0.039)$ \\
Constant & $0.716^{* * *}$ & $0.927^{* * *}$ \\
& $(0.060)$ & $(0.032)$ \\
$\mathrm{R}^{2}$ & 0.146 & 0.130 \\
Observations & 253 & 290 \\
\hline
\end{tabular}

The table above reports estimated treatment effects on the likelihood of having any nonzero transactions. Column 1 estimates effects in Ekiti state; column 2 does so in Niger state. Both columns include Local Government Authority (stratum) fixed effects. All standard errors are clustered at the level of the facility. * denotes significance at the $10 \%$ level, $* *$ at the $5 \%$ level, and $* * *$ at the $1 \%$ level.

Table A2

Appendix table: differences between states, selected DHS 2013 statistics.

\begin{tabular}{lll}
\hline & $\begin{array}{l}\text { Ekiti } \\
{[1]}\end{array}$ & $\begin{array}{l}\text { Niger } \\
{[2]}\end{array}$ \\
\hline Percent of children whose births are registered & 50.5 & 14.1 \\
Percent of children with a birth certificate & 29.2 & 5.6 \\
Percent of women unable to read & 7.5 & 68.5 \\
Percent of women with no formal schooling & 2.0 & 65.8 \\
Percent of women with post-primary schooling & 85.2 & 24.7 \\
Median years of schooling among women & 11.2 & 0.0 \\
Percent of men unable to read & 4.0 & 34.3 \\
Percent of men with no formal schooling & 1.0 & 31.1 \\
Percent of men with post-primary schooling & 90.5 & 57.6 \\
Median years of schooling among men & 11.5 & 8.8 \\
$\mathrm{R}^{2}$ & 0.146 & 0.130 \\
Observations & 253 & 290 \\
\hline
\end{tabular}

All figures above come from the 2013 Demographic and Health Survey Final Report for Nigeria (National Population Commission and ICF International, 2013).

Table A3

Appendix table: Main effects with log monthly patients as control.

\begin{tabular}{|c|c|c|c|c|}
\hline & \multicolumn{2}{|l|}{ Ekiti } & \multicolumn{2}{|l|}{ Niger } \\
\hline & [1] & [2] & [3] & [4] \\
\hline Social recognition & $\begin{array}{l}0.123^{* * *} \\
(0.049)\end{array}$ & $\begin{array}{l}0.098^{* *} \\
(0.043)\end{array}$ & $\begin{array}{l}-0.021 \\
(0.028)\end{array}$ & $\begin{array}{l}-0.010 \\
(0.025)\end{array}$ \\
\hline Baseline score & & $\begin{array}{l}0.286^{* * * *} \\
(0.091)\end{array}$ & & $\begin{array}{l}0.255 \\
(0.185)\end{array}$ \\
\hline Constant & $\begin{array}{l}0.682^{* * *} \\
(0.136)\end{array}$ & $\begin{array}{l}0.462^{* * *} \\
(0.149)\end{array}$ & $\begin{array}{l}0.577^{* * * *} \\
(0.081)\end{array}$ & $\begin{array}{l}0.457^{* \cdots *} \\
(0.110)\end{array}$ \\
\hline $\mathrm{R}^{2}$ & 0.239 & 0.301 & 0.279 & 0.325 \\
\hline Observations & 180 & 180 & 273 & 269 \\
\hline
\end{tabular}

Table A4

Appendix table showing treatment effects on possible spillover outcomes.

\begin{tabular}{lll}
\hline & $\begin{array}{l}\text { Wait time } \\
{[1]}\end{array}$ & $\begin{array}{l}\text { Treatment duration } \\
{[2]}\end{array}$ \\
\hline Social recognition & 0.584 & -0.432 \\
\multirow{2}{*}{ Social recognition $\times$ Ekiti } & $(0.767)$ & $(1.256)$ \\
& -0.168 & -0.502 \\
$\mathrm{R}^{2}$ & $(2.322)$ & $(2.050)$ \\
& 0.217 & 0.199 \\
\hline
\end{tabular}

Wait times and treatment durations, taken from exit surveys of patients, are measured in minutes. All standard errors are clustered at the level of the facility. * denotes significance at the $10 \%$ level, ** at the $5 \%$ level, and $* * *$ at the $1 \%$ level. 
Table A5

LASSO-selected specifications.

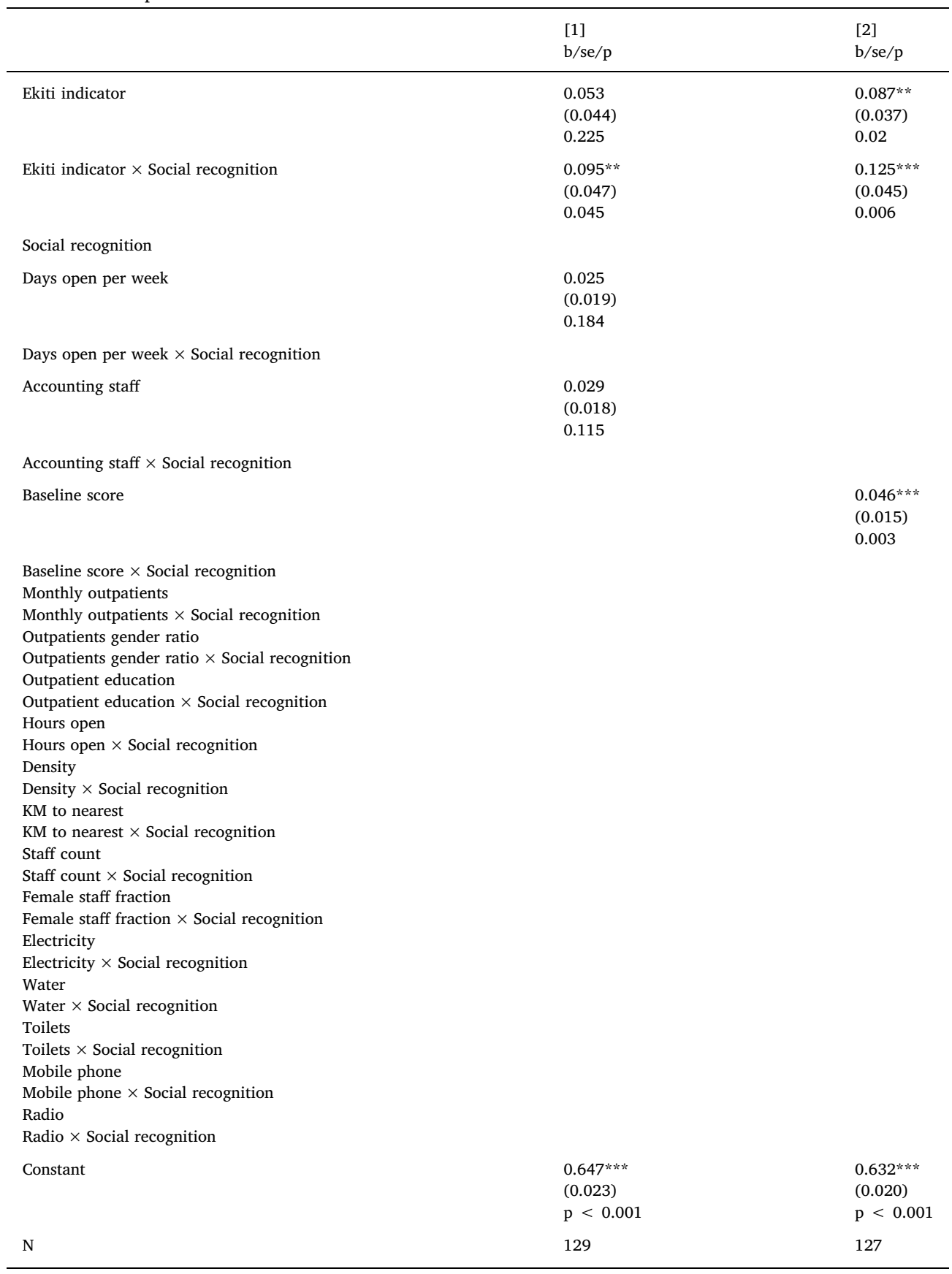

Column 1, above, shows results from OLS regressions using LASSO-selected variables when all variables (even those sometimes missing) are included for all observations. Column 2 shows analogous results where we exclude outpatient education and its interaction (which are missing for ten observations), and we restrict analysis to a set of $127 \mathrm{ob}-$ servations for which no other variable is missing.

\section{References}

Ahrens, A., Hansen, C. B. \& Schaffer, M. E. (2018). Lasso2: Program for lasso, square-root lasso, elastic net, ridge, adaptive lasso and post-estimation OLS. http://ideas.repec $\mathrm{org} / \mathrm{c} / \mathrm{boc} /$ bocode/s458458.html (Revised 24 January 2019).

Aghion, P., \& Tirole, J. (1997). Formal and real authority in organizations. Journal of Political Economy, 105(1), 1-29.

Allcott, H. (2015). Site selection bias in program evaluation. Quarterly Journal of Economics, 130(3), 1117-1165.

Andersen, S., Ertac, S., Gneezy, U., List, J. A., \& Maximiano, S. (2013). Gender, competitiveness, and socialization at a young age: Evidence from a matrilineal and a patriarchal society. Review of Economics and Statistics. 95(4), 1438-1443.

Andrews. I., \& Oster, E. (2017). Weighting for external validity. NBER Working Paper No. 23826. National Bureau of Economic Research, Cambridge, MA.
Ashraf, N. (2013). Rx: Human nature: How behavioral economics is promoting better health around the world. Harvard Business Review, 91(4), 119-125.

Ashraf, N. (2018). Bandiera social incentives in organizations. Annual Review of Economics, 10, 439-463.

Ashraf, N., Bandiera, O., \& Jack, K. (2014). No margin, no mission? A field experiment for public services delivery. Journal of Public Economics, 120, 1-17.

Ashraf, N., Bandiera, O., \& Lee, S. S. (2016). Do-gooders and Go-getters: Career Incentives, Selection, and Performance in Public Service Delivery. London School of Economics, London: Unpublished paper.

Banerjee, A., Karlan, D., \& Zinman, J. (2015). Six randomized evaluations of microcredit: Introduction and further steps. American Economic Journal: Applied Economics, 7(1), $1-21$.

Bardhan, P. (2016). State and development: The need for a reappraisal of the current literature. Journal of Economic Literature, 54(3), 862-892.

Basinga, P., Gertler, P. J., Binagwaho, A., Soucat, A. L., Sturdy, J., \& Vermeersch, C. M. 
(2011). Effect on maternal and child health services in Rwanda of payment to primary health-care providers for performance: An impact evaluation. The Lancet, 377(9775), 1421-1428.

Bates, M. A., \& Glennerster, R. (2017). The generalizability puzzle. Stanford Social Innovation Review, Summer 2017, 50-54.

Benartzi, S., Beshears, J., Milkman, K. L., Sunstein, C. R., Thaler, R. H., Shankar, M., et al. (2017). Should governments invest more in nudging? Psychological Science, 28(8), 1041-1055.

Besley, T., \& Ghatak, M. (2008). Status incentives. American Economic Review, 98(2), 206-211.

Brock, J. M., Lange, A., \& Leonard, K. L. (2016). Generosity and prosocial behavior in healthcare provision evidence from the laboratory and field. Journal of Human Resources, 51(1), 133-162.

Bhuller, M., Dahl, G. B., Loke, K. V., \& Mogstad, M. (2018). Incarceration spillovers in criminal and family networks. NBER Working Paper, 24878.

Björkman, M., \& Svensson, J. (2009). Power to the people: Evidence from a randomized field experiment on community-based monitoring in Uganda. The Quarterly Journal of Economics, 124(2), 735-769.

Bold, T., Kimenyi, M., Mwabu, G., Ng'ang'a, A., \& Sandefur, J. (2013). Scaling up what works: experimental evidence on external validity in kenyan education. Working Paper 321, Center for Global Development, Washington, DC.

Butera, L., Metcalfe, R., Morrison, W., \& Taubinsky, D. (2019). The deadweight loss of social recognition. NBER Working Paper No. 25637.

Cassar, L., \& Meier, S. (2018). Nonmonetary incentives and the implications of work as a source of meaning. Journal of Economic Perspectives, 32(3), 215-238.

Chekroun, P., \& Brauer, M. (2002). The bystander effect and social control behavior: The effect of the presence of others on people's reactions to norm violations. European Journal of Social Psychology, 32(6), 853-867.

Chetty, R., Mobarak, M., \& Singhal, M. (2014). Increasing tax compliance through social recognition. Policy Brief.

Das, A., Friedman, J., \& Kandpal, E. (2018). Does involvement of local NGOs enhance public service delivery? Cautionary evidence from a malaria-prevention program in India. Health Economics, 27, 172-188.

Dobbie, W., Goldon, J, \& Yang, C. S. (2018). The effects of pretrial detention on conviction, future crime, and employment: evidence from randomly assigned judges. American Economic Review 108(2), 201-240.

Dunsch F. A., Evans, D. K., Eze-Ajoku, E., Macis, M. (2017). Management, supervision, and health care: a field experiment. IZA Discussion Paper no. 10967.

Eckel, C. C., \& Grossman, P. J. (1998). Are women less selfish than men? Evidence from dictator experiments. The Economic Journal. 108(448), 726-735.

Evans, P., \& Rauch, J. E. (1999). Bureaucracy and growth: A cross-national analysis of the effects of 'Weberian' state structures on economic growth. American Sociological Review, 64(5), 748-765.

Galiani, S., Gertler, P., \& Romero, M. (2018). How to make replication the norm. Nature, 554(7693), 417-419.

Gauri, V., et al. (2015). The Costa Rican supreme court's compliance monitoring system. The Journal of Politics, 77(3), 774-786.

Gauthier, B., Pimhidzai, O., Saleh, K. (2018). Resource tracking in primary health care in Nigeria: case study from Niger and Ekiti states. Vol I and II, World Bank, Washington, D.C.

Gonçalves, S. (2014). The effects of participatory budgeting on municipal expenditures and infant mortality in Brazil. World Development, 53(1), 94-110.

Hirschman, A. O. (1973). An alternative explanation of contemporary harriednes. The Quarterly Journal of Economics, 87(4), 634-637.

Holmstrom, B., \& Milgrom, P. (1991). Multitask principal-agent analyses: incentive contracts, asset ownership, and job design. Journal of Law, Economics, and Organization, 7, 24-52 http://dx.doi.org/10.1093/jleo/7.special issue.24.

Hunt, M. (1997). How science takes stock: The story of meta-analysis. Russell Sage Foundation.

Khemani, S. (2006). Local government accountability for health service delivery in Nigeria. Journal of African Economies, 15(2), 285-312.
Kosfeld, M., \& Neckermann, S. (2011). Getting more work for nothing? Symbolic awards and worker performance. American Economic Journal: Microeconomics, 3, 86-99.

Kremer, M., \& Glennerster, R. (2011). Improving health in developing countries: Evidence from randomized evaluations. Handbook of Health Economics: Vol. 2, (pp. 201-315). Elsevier.

Kremer, M., Miguel, E., \& Thornton, R. (2009). Incentives to learn. Review of Economics and Statistics, 91(3), 437-456.

Larkin I. (2011) Paying $\$ 30,000$ for a gold star: An empirical investigation into the value of peer recognition to software salespeople. Mimeo.

Levitt, S. D., \& List, J. A. (2009). Field experiments in economics: The past, the present, and the future. European Economic Review, 53(1), 1-18.

Maniadis, Z., Tufano, F., \& List, J. A. (2014). One swallow doesn't make a summer: New evidence on anchoring effects. American Economic Review, 104(1), 277-290.

Mathauer, I., \& Imhoff, I. (2006). Health worker motivation in Africa: The role of nonfinancial incentives and human resource management tools. Human Resources for Health, 4(1), 24

Mazar, N., \& Hawkins, S. A. (2015). Choice architecture in conflicts of interest: defaults as physical and psychological barriers to (Dis)honesty. Journal of Experimental Social Psychology, 59(July), 113-117.

Moldovanu, B., Sela, A., \& Shi, X. (2007). Contests for status. Journal of Political Economy, 115(2), 338-363.

Mullainathan, S., \& Shafir, E. (2013). Scarcity: Why Having Too Little Means So Much. Macmillan.

Muralidharan, K., \& Sundararaman, V. (2011). Teacher performance pay: Experimental evidence from India. Journal of Political Economy, 119(1), 39-77.

National Population Commission and ICF International (2013). Nigeria Demographic and Health Survey.

Nelson, R. B. (2001). Factors that encourage or inhibit the use of non-monetary recognition by U.S. managers. Dissertation, Claremont Graduate University. Available at < http://novascotia.ca/psc/pdf/employeeCentre/recognition/toolkit/step1/ BobsPhDDissertation.pdf > (Accessed October 20, 2016).

Olken, B. A. (2007). Monitoring corruption: Evidence from a field experiment in Indonesia. Journal of Political Economy, 115(2), 200-249.

Petticrew, M., \& Roberts, H. (2008). Systematic reviews in the social sciences: A practical guide. John Wiley \& Sons.

Piff, P. K., Kraus, M. W., Côté, S., Cheng, B. H., \& Keltner, D. (2010). Having less, giving more: The influence of social class on prosocial behavior. Journal of Personality and Social Psychology, 99(5), 771.

Prendergast, C. (1999). The provision of incentives in firms. Journal of Economic Literature, 37(1), 7-63.

Reinikka, R., \& Svensson, J. (2004). Local capture: Evidence from a central government transfer program in Uganda. Quarterly Journal of Economics, 119(2), 679-705.

Rasul, I., \& Rogger, D. (2018). Management of bureaucrats and public service delivery: Evidence from the Nigerian civil service. Economic Journal, 128(608), 413-446.

Rogger, D. (2017) Who serves the poor? Surveying civil servants in the developing world. Policy Research Working Paper 8051, World Bank Group, Washington, DC.

Rosenzweig, M., Udry, C. (2016) External validity in a stochastic world. NBER Working Paper No. 22449. National Bureau of Economic Research, Cambridge, MA.

Ryan, R. M., \& Deci, E. L. (2000). Intrinsic and extrinsic motivations: classic definitions and new directions. Contemporary Educational Psychology, 25(2000), 54-67.

Stajkovic, A. D., \& Luthans, F. (1997). A meta-analysis of the effects of organizational behavior modification on task performance, 1975-95. Academy of Management Journal, 40(5), 1122-1149.

Stilwell, B. (2001). Health worker motivation in Zimbabwe. Unpublished paper/internal report for the Department of Organization of Health Care Delivery.

Thaler, R., \& Sunstein, C. R. (2008). Nudge: Improving Decisions about Health, Wealth, and Happiness. New York: Penguin Books.

World Bank (2004). Making Services Work for Poor People. Washington, D.C.: World Development Report.

World Bank (2015). Mind, society and behavior. World Development Report. Washington, D.C. 